\title{
Unified parameterization of the planetary boundary layer and shallow convection with a higher-order turbulence closure in the Community Atmosphere Model: single-column experiments
}

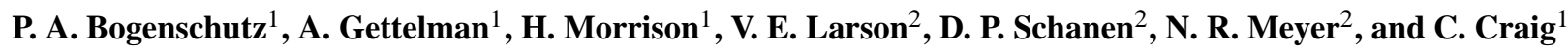 \\ ${ }^{1}$ National Center for Atmospheric Research, Boulder, Colorado, USA \\ ${ }^{2}$ University of Wisconsin-Milwaukee, Milwaukee, Wisconsin, USA
}

Correspondence to: P. A. Bogenschutz (bogensch@ucar.edu)

Received: 5 June 2012 - Published in Geosci. Model Dev. Discuss.: 6 July 2012

Revised: 28 September 2012 - Accepted: 2 October 2012 - Published: 14 November 2012

\begin{abstract}
This paper describes the coupling of the Community Atmosphere Model (CAM) version 5 with a unified multi-variate probability density function (PDF) parameterization, Cloud Layers Unified by Binormals (CLUBB). CLUBB replaces the planetary boundary layer (PBL), shallow convection, and cloud macrophysics schemes in CAM5 with a higher-order turbulence closure based on an assumed PDF. Comparisons of single-column versions of CAM5 and CAM-CLUBB are provided in this paper for several boundary layer regimes. As compared to large eddy simulations (LESs), CAM-CLUBB and CAM5 simulate marine stratocumulus regimes with similar accuracy. For shallow convective regimes, CAM-CLUBB improves the representation of cloud cover and liquid water path (LWP). In addition, for shallow convection CAM-CLUBB offers better fidelity for subgrid-scale vertical velocity, which is an important input for aerosol activation. Finally, CAM-CLUBB results are more robust to changes in vertical and temporal resolution when compared to CAM5.
\end{abstract}

\section{Introduction}

Boundary layer clouds play a key role in the climate system on several accounts. They modulate the Earth's radiation balance (Hartmann et al., 1992), remain a crux in understanding cloud feedbacks (Stephens et al., 2005), and play important roles in understanding the indirect aerosol effects on climate (Heintzenberg and Charlson, 2009). Poor representation of low clouds, including stratocumulus and cumu- lus, in climate models has been thought to be the contributing factor to uncertainty in future climate prediction (Webb et al., 2006; Bony and Dufresne, 2005). In addition, several authors (e.g. Gettelman et al., 2012; Medeiros et al., 2008) find that low clouds, particularly shallow cumulus, contribute significant uncertainty to climate sensitivity experiments. Therefore, stratocumulus, shallow cumulus, and transitional types (i.e. cumulus under stratocumulus) of boundary layer regimes must be well represented in global climate models (GCMs) for the simulated climate to be represented with fidelity. The challenge in simulating cloud-topped planetary boundary layers (PBLs) rests in the fact that the close coupling and interactions between microphysics, radiation, and turbulence occur on much smaller scales than grid sizes used in modern GCMs (Schubert et al., 1979). Additionally, the turbulent properties and statistics often vary continuously between cloud types, such as stratocumulus and tradewind cumulus, which suggests the use of so-called "unified" parameterizations that treat all PBL clouds using the same equation set (Lappen and Randall, 2001).

Over the past decade, great advances have been made in representation of PBL clouds in GCMs. For instance, the PBL (Holtslag and Boville, 1993) and shallow cumulus parameterization (Hack, 1994) in the Community Atmosphere Model (CAM) version 4.0 did not assume direct interaction with each other, often leading to inconsistencies. The Holtslag and Boville (1993) PBL scheme is a downgradient diffusion model which includes counter-gradient fluxes. However, this scheme assumes that the surface fluxes are the only energy source for turbulence. In addition, only dry 
conserved variables are used which is not compatible with a shallow moist convection scheme. CAM4 often simulates both an underrepresentation and misrepresentation of lowlevel clouds (Kay et al., 2012). CAM5 introduced a major improvement in the treatment of cloud-topped boundary layers with the inclusion of the University of Washington Moist Turbulence scheme (UWMT; Bretherton and Park, 2009) and the UW shallow convection scheme (UWSC; Park and Bretherton, 2009). Unlike CAM4, the UWMT and UWSC schemes are designed to interact with each other. Other GCMs have also updated their parameterizations for shallow convection and turbulent transports over the last decade (e.g. Lock et al., 2000; von Salzen and McFarlane, 2002). In addition, super-parameterized GCMs are also in the process of updating their treatment of shallow convection and PBL turbulence in coarse-grid cloud resolving models (e.g. Cheng et al., 2011; Bogenschutz and Krueger, 2012; Larson et al., 2012).

This paper describes the coupling of CAM with a relatively new turbulence and shallow convection scheme. Known as Cloud Layers Unified by Binormals (CLUBB; Golaz et al., 2002, 2007; Larson and Golaz, 2005), this parameterization is based on a higher-order turbulence closure that uses an assumed trivariate probability density function (PDF) of vertical velocity, temperature, and total water in order to close turbulent moments and cloud macrophysical quantities in a physically consistent manner. Whereas the UWMT scheme is based on downgradient diffusion, CLUBB integrates the predictive equations of four first-order moments, eight second-order moments, (including the vertical transports of heat and moisture) and one third-order moment. Predicting higher-order moments allows for the representation of non-local sources and sinks of turbulent transport. CLUBB is also flexible in that it utilizes an assumed double Gaussian PDF to compute important cloud macrophysical properties such as cloud fraction and liquid water mixing ratio consistently with the PDF of total water. The assumed double Gaussian PDF accommodates trade-wind cumulus regimes, whose vertical velocity and cloud properties tend to be highly skewed, as well as stratocumulus, whose vertical velocity and cloud properties tend to be closer to Gaussian (Larson et al., 2002).

The computational cost of CLUBB is reduced relative to a to full third-order turbulence closure because any turbulent moments that are a combination of vertical velocity, temperature, moisture, or liquid water can be closed by integrating over the PDF. This avoids the need to predict the additional moments or to use closure assumptions that may or may not be consistent with each other. Cheng and $\mathrm{Xu}$ (2006) show that this "incomplete" third-order closure using an assumed PDF more accurately represents boundary layer clouds compared to fully prognostic third-order closure, due to consistent closure relationships via the assumed PDF. In addition, a scheme such as CLUBB is attractive for use in a GCM because it provides statistical moments of subgrid-scale (SGS) variability. Due to recent upgrades, some GCMs (such as CAM) now include double-moment microphysics (MG, Morrison and Gettelman, 2008) as well as modal prognostic aerosol schemes (Liu et al., 2012), and hence it is now possible to represent indirect aerosol effects in these GCMs. Cloud-aerosol interactions could benefit from a unified parameterization of the PBL and shallow convection, because a unified parameterization can drive a single microphysics scheme (MG). Guo et al. (2010) presented SCM results of CLUBB implemented into the Geophysical Fluid Dynamics Laboratory (GFDL) Atmosphere Model (AM) version 3 (Donner et al., 2011). This paper marks the first time that such a parameterization has been implemented in CAM.

This paper is organized as follows. Section 2 provides a brief description of CAM5 and details the coupling of CAM with CLUBB. Section 3 shows single-column simulations by CAM5 and CAM-CLUBB for various boundary layer cloud regimes. Here sensitivities to the time step and vertical resolution are elucidated. Section 4 provides discussions, conclusions, and plans for future work.

\section{Model development}

\subsection{Brief description of CAM5}

The Community Atmosphere Model (CAM) version 5 (Neale et al., 2011) is used as the control (hereafter referred to as CAM-BASE) model in this study. CAM-BASE represents nearly a complete overhaul in physical parameterization options from CAM4, with the exception of the deep convection scheme (Zhang and McFarlane, 1995; Neale et al., 2008; Richter and Rasch, 2008). The boundary layer scheme is based on downgradient diffusion of moist conserved variables (UWMT; Bretherton and Park, 2009). The shallow convection scheme in CAM-BASE is Park and Bretherton (2009; UWSC), while cloud macrophysics is computed according to Park (2010). Morrison and Gettelman (MG; 2008) twomoment stratiform microphysics for both liquid and ice is used in CAM-BASE, as described in Gettelman et al. (2010). Aerosols are predicted according to Liu et al. (2012).

\subsection{Description of CAM-CLUBB}

The new configuration of CAM, referred to as CAMCLUBB, differs from CAM-BASE in terms of physical parameterization options. In CAM-CLUBB, the UWMT, UWSC, and the Park cloud macrophysics schemes are all turned off. CLUBB (Golaz et al., 2002) is therefore responsible for providing tendencies due to boundary layer mixing and shallow convection to CAM in a single parameterization call. This is attractive because it ensures that there are no inconsistencies between separate PBL and shallow convection schemes, for example. 
CLUBB is inherently different from the moist turbulence and shallow convection schemes currently used in CAMBASE in the sense that it represents what is commonly referred to as an "incomplete" (i.e. Cheng and Xu, 2006; Golaz et al., 2002) predictive third-order turbulence closure. This closure assumes a PDF shape in order to determine cloud macrophysics quantities as well as to close turbulent moments that are needed in the governing equations. The current version of CLUBB predicts $\overline{\theta_{1}}$ (liquid water potential temperature), $\overline{q_{\mathrm{t}}}$ (total water mixing ratio), $\bar{u}$ (zonal wind), $\bar{v}$ (meridional wind), $\overline{u^{\prime 2}}, \overline{v^{\prime 2}}, \overline{\theta_{1}^{\prime 2}}, \overline{q_{\mathrm{t}}^{\prime 2}}, \overline{\theta_{1}^{\prime} q_{\mathrm{t}}^{\prime}}, \overline{w^{\prime} q_{\mathrm{t}}^{\prime}}, \overline{w^{\prime} \theta_{1}^{\prime}}, \overline{w^{\prime 2}}$, and $\overline{w^{\prime 3}}$ (where $w$ is vertical velocity). Formulations for these predictive equations can be found in Golaz et al. (2007), and the formulations for $\overline{u^{\prime 2}}$ and $\overline{v^{\prime 2}}$ can be found in Larson et al. (2012). CLUBB does not predict the momentum fluxes $\overline{u^{\prime} w^{\prime}}$ and $\overline{v^{\prime} w^{\prime}}$, as these terms are diagnosed according to Golaz et al. (2002). Any higher-order moment in the form of $\overline{w^{\prime m} \theta_{1}^{\prime n} q_{t}^{\prime o} q_{1}^{\prime p}}$ (where $q_{1}$ is liquid water mixing ratio) can be closed by integrating over the assumed triple-joint PDF. The triple joint PDF, $P\left(\theta_{\mathrm{l}}, q_{\mathrm{t}}, w\right)$, is assumed to be an analytic double Gaussian PDF. Larson et al. (2002) and Bogenschutz et al. (2010) show that a PDF of a double Gaussian form is more flexible and more realistic than a single Gaussian or delta function as it can properly represent the often skewed distributions of a cumulus layer. For the transport of scalars in CAM-CLUBB (such as ice mixing ratio, ice number concentration, chemistry constituents, etc.), a simple downgradient diffusion model is used with an eddy diffusivity coefficient as a function of CLUBB's turbulence length scale and turbulence kinetic energy. Future implementations of CAM-CLUBB could transport scalars through CLUBB's high-order predictive equations.

In addition to providing temperature, moisture, and momentum tendencies due to boundary layer turbulence and convection, CLUBB also computes cloud fraction $(C)$ and cloud liquid water mixing ratio from the assumed joint PDF. These are important macrophysical cloud quantities that are needed for computation of radiative, microphysical, and aerosol processes. In addition, a SGS vertical velocity is needed for aerosol activation because droplet activation depends on local rather than grid-scale vertical velocity. In CAM-BASE this is done by deriving the SGS vertical velocity $\left(w^{\prime}\right)$ from the diagnosed TKE computed in the UWMT scheme, as described in Morrison and Gettelman (2008). In CAM-CLUBB the $w^{\prime}$ is derived from the predicted value of $\overline{w^{\prime 2}}$ and in large eddy simulations (LESs) it is computed as $w^{\prime}=\sqrt{\overline{w^{\prime 2}}}$.

Currently there is no change in the formulation of the double moment MG microphysics scheme to account for the SGS variability predicted by CLUBB. However, future implementations of CAM-CLUBB will include revised formulations to take into account SGS $\overline{q_{l}^{\prime 2}}$ and $\overline{q_{l}^{\prime} q_{r}^{\prime}}$ (where $q_{r}$ is rain mixing ratio), for instance, for consideration in auto- conversion and accretion process rates. In addition, aerosol activation could benefit from CLUBB's SGS PDF by integrating over the PDF of vertical velocity (Ghan et al., 1997) as calculation at a single updraft velocity is done only for computation expedience and it is an approximation that is questionable if the PDF of vertical velocity is skewed.

Larson et al. (2012) list several advantages of CLUBB for application to cloud resolving models, and many of those advantages also pertain to GCMs. Among the most important advantages is that CLUBB helps solve the problem of separate and hence inconsistent microphysics parameterizations. For instance, convective schemes in GCMs, such as the deep and shallow convection schemes in CAM-BASE, often contain their own microphysics parameterizations, which differ from the stratiform microphysics. Separate microphysics parameterizations have been developed, likely because subgrid variability in cumulus clouds is quite different from stratiform clouds. However, since the fundamental equations of microphysics are the same in cumulus and stratocumulus, the use of separate microphysics parameterizations for these two regimes is physically undesirable. CLUBB, on the other hand, can drive the MG microphysics scheme for both regimes since it uses a single joint PDF that is general enough to represent both cumulus and stratocumulus. This negates the need for a separate shallow cumulus microphysics parameterization such as Park and Bretherton (2009) and offers a more unified treatment of cloud-aerosol interactions and boundary-layer clouds. However, it should be mentioned that a tighter coupling between CLUBB and microphysics in future versions of CAM-CLUBB will also help in representing aerosol effects on cloud dynamics (Guo et al., 2011).

\section{Single-column experiments}

We use single-column CAM (SCAM) simulations as an initial framework to test the implementation of CLUBB into CAM, since it avoids the computational cost and complexity of a full GCM (Randall et al., 1996). In addition, singlecolumn testing allows for direct comparison with LES, which use the same large-scale forcing and initial conditions as our tests. We test CAM-CLUBB on six diverse regimes of boundary layer clouds, as listed in Table 1 . These range from trade-wind cumulus, stratocumulus, a transitional regime in which cumulus is present under stratocumulus, to continental shallow cumulus. LESs have been performed for these regimes using either the COAMPS LES (Golaz et al., 2005) or the System for Atmospheric Modeling (SAM; Khairoutdinov et al., 2003). These LES simulations provide a benchmark for comparisons with the SCAM simulation.

Although the operational version of CAM uses coarse vertical grid spacing $(\Delta z)$ corresponding to 30 grid levels and a time step $(\Delta t)$ of $1800 \mathrm{~s}$, it is important to address sensitivity to changes in $\Delta z$ and $\Delta t$ in order to anticipate physics parameterization performance when CAM's $\Delta z$ and $\Delta t$ are 
Table 1. Summary of cases used for single-column CAM testing

\begin{tabular}{|c|c|c|c|}
\hline Cases & Full name & Regime type & References \\
\hline DYCOMS2-RF01 & $\begin{array}{l}\text { Dynamics and } \\
\text { Chemistry of } \\
\text { Stratocumulus }\end{array}$ & $\begin{array}{c}\text { Maritime } \\
\text { stratocumulus }\end{array}$ & Stevens et al. (2005) \\
\hline DYCOMS2-RF02 & $\begin{array}{l}\text { Dynamics and } \\
\text { Chemistry of } \\
\text { Stratocumulus }\end{array}$ & $\begin{array}{c}\text { Maritime } \\
\text { drizzling } \\
\text { stratocumulus }\end{array}$ & Ackerman et al. (2009) \\
\hline ATEX & $\begin{array}{c}\text { Atlantic Trade } \\
\text { Wind Experiment }\end{array}$ & $\begin{array}{l}\text { Maritime } \\
\text { cumulus under } \\
\text { stratocumulus }\end{array}$ & Stevens et al. (2001) \\
\hline BOMEX & $\begin{array}{c}\text { Barbados Oceanographic } \\
\text { and Meteorological } \\
\text { Experiment }\end{array}$ & $\begin{array}{l}\text { Marine shallow } \\
\text { cumulus }\end{array}$ & Siebesma et al. (2003) \\
\hline RICO & $\begin{array}{l}\text { Rain in Cumulus } \\
\text { Over Ocean }\end{array}$ & $\begin{array}{l}\text { Precipitating } \\
\text { marine shallow } \\
\text { cumulus }\end{array}$ & Rauber et al. (2003) \\
\hline ARM & $\begin{array}{c}\text { Atmospheric } \\
\text { Radiation Measurement }\end{array}$ & $\begin{array}{c}\text { Continental } \\
\text { shallow cumulus }\end{array}$ & Brown et al. (2002) \\
\hline
\end{tabular}

refined with advances in computational performance. For this reason, the BASE and CLUBB versions of CAM are configured with a variety of host model time steps $(\Delta t)$ and vertical grid spacings $(\Delta z)$. For each cloud case, the number of levels tested are $30,60,90,120,150,180,210$, and 240, while the values of $\Delta t$ tested are 60, 300, 600, 900, 1200, 1500, 1800, 2100 , and $2400 \mathrm{~s}$. For each $\Delta z$ configuration, the model top pressure is $\sim 2.5 \mathrm{mb}$, with a stretched grid that is refined near the surface. Each combination of $\Delta z$ and $\Delta t$ are tested, yielding a total of 72 tests for each case and model configuration. In all simulations, the vertical grid seen by all parameterizations, including CLUBB, is the same as the vertical grid of the host model. In addition, all parameterizations in CAM-BASE use the same time step as the host model. However, in CAM-CLUBB, the CLUBB time step is held fixed at 5 min (Golaz et al., 2007), except for the simulation with the host $\Delta t=60 \mathrm{~s}$; in that case, CLUBB's $\Delta t$ is also $60 \mathrm{~s}$.

One may argue that the relatively short CLUBB time step does not result in a fair comparison of CAM-CLUBB and CAM-BASE at similar host model time steps. However, it is important to point out that UWMT, UWSC, and Park macrophysics schemes all have their own sub-stepping loops built into the parameterizations, which are analogous to CLUBB's sub-time step. The default number of iterations is five for UWMT, two for UWSC, and two for Park macrophysics. Experimenting with the number of iteration cycles in CAMBASE parameterizations is explored in this paper. However, it is important to note that, at the operational 1800-s time step, CAM-CLUBB's computational cost is quite comparable to CAM-BASE, as it is only $4 \%$ more expensive. When the host $\Delta t<1200 \mathrm{~s}$, then CAM-CLUBB is slightly cheaper than CAM-BASE. For the host model time steps of $2100 \mathrm{~s}$ and $2400 \mathrm{~s}$, CAM-CLUBB is only $6 \%$ and $10 \%$ more expensive, respectively, than CAM-BASE. Because using a 5-min time step for CLUBB does not impose undue computational cost, there is limited incentive to lengthen CLUBB's time step.

In this study, we will examine how CAM-BASE and CAM-CLUBB represent SGS vertical velocity and droplet number concentration since these components are important for aerosol activation and indirect aerosol effects. Nevertheless, this study mostly focuses on assessing how CAM-BASE and CAM-CLUBB differ in their representation of cloud macrophysical quantities such as cloud fraction and cloud mixing ratio. To help isolate the cloud effects, we use prescribed aerosols, instead of the predictive aerosol option in CAM. While this study only simulates cloudy boundary layer regimes, the deep convection scheme (Zhang and McFarlane, $1995)$ is left turned on but is largely inactive for both CAMBASE and CAM-CLUBB for all simulations presented.

\subsection{Trade wind cumulus}

This section presents results of two trade-wind cumulus cases: one non-precipitating (BOMEX) and one precipitating (RICO).

Figure 1 displays model sensitivity to $\Delta t$ and $\Delta z$ for both CAM-BASE and CAM-CLUBB for the BOMEX case of non-precipitating shallow cumulus. The top row shows the biases of integrated low cloud amount averaged over the last $2 \mathrm{~h}$ of the simulation for each CAM configuration. The LES value $(C=0.12)$ is denoted in the model configuration cell 


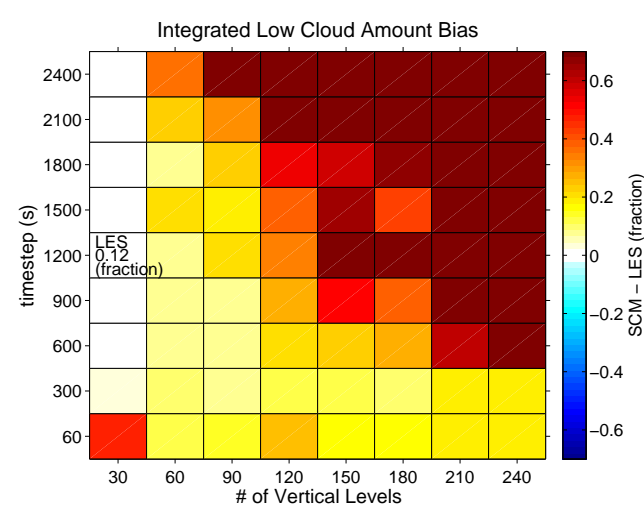

(a) CAM-BASE

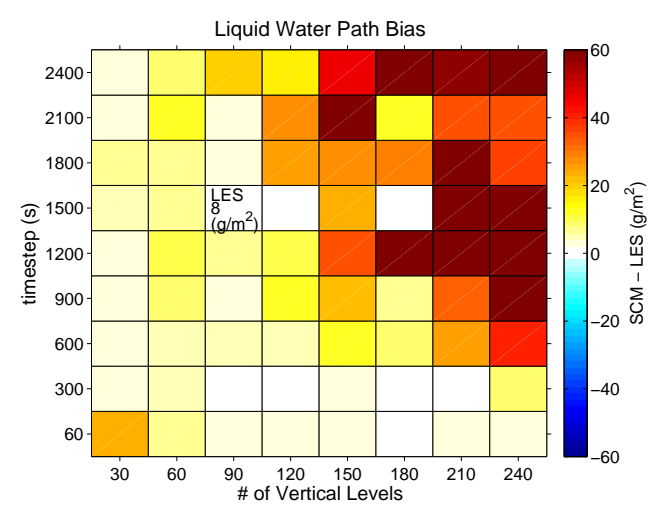

(c) CAM-BASE

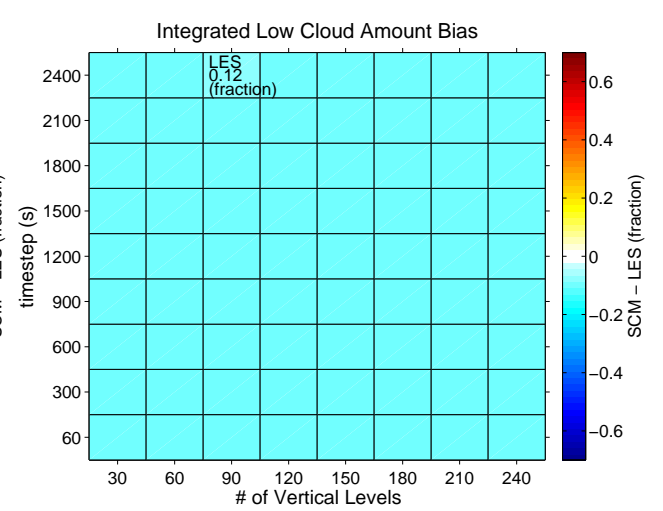

(b) CAM-CLUBB

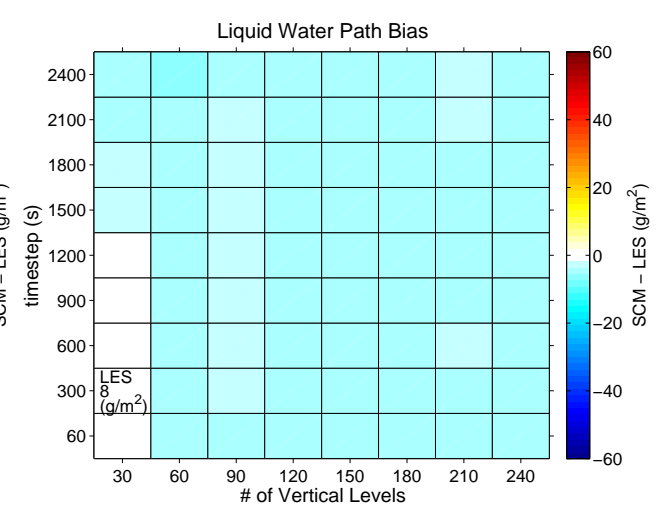

(d) CAM-CLUBB

Fig. 1. Biases of vertically integrated low cloud amount (a, b) and liquid water path (c, d) from SCAM-BASE (a, c) and SCAM-CLUBB (b, d). Displayed is the BOMEX case of non-precipitating trade-wind cumulus, averaged over hours 4-6 of the simulation. Plotted in each cell is the bias computed with respect to LES for a different value of $\Delta z$ and $\Delta t$. The cell marked "LES" indicates the configuration with the best match with the large eddy simulation (LES) for the particular variable. The value in this box is the value computed by LES for this regime.

that corresponds to the best match with LES. Light hues indicate a relatively small bias, whereas dark hues represent a large bias. White cells indicate near perfect agreement with LES. The BOMEX case is characterized by small cloud fraction, which is often difficult for moist parameterizations to simulate accurately due to the highly skewed nature of the cloud and turbulence properties of this regime. This is true for CAM-BASE, which tends to overestimate the integrated cloud fraction at most configurations of $\Delta t$ and $\Delta z$, although the CAM-BASE bias is small at operational resolution. The overestimate becomes most pronounced when the number of levels and $\Delta t$ increases. Similar sensitivities can also be found in the temporally averaged liquid water path (LWP) results (Fig. 1c) for CAM-BASE. CAM-CLUBB, on the other hand, shows a slight negative bias for both integrated cloud fraction and LWP. However, it shows much less sensitivity to changes in $\Delta t$ and $\Delta z$, even for configurations with high vertical resolution and coarse time step, which is an encouraging result.

Another experiment was performed in which the number of allowed iterations for the UWMT, UWSC, and Park macrophysics were all set equal to the number of CLUBB sub-time steps for each respective host model time step. Results (not shown) looked nearly identical to those of Fig. 1. Increasing the number of iterations for CAM-BASE parameterizations for BOMEX at high vertical resolution and coarse time step smooths the mean time profiles, but otherwise does not much change the overall result. In addition, these SCAM-BASE simulations were more expensive than SCAM-CLUBB simulations for nearly all $\Delta t$ configurations.

Figure 2 displays the horizontally and temporally averaged profiles of cloud fraction and $q_{1}$ for simulations using $\Delta t=300 \mathrm{~s}$, with 30 and 240 vertical levels. While this time step is much smaller than that traditionally used in GCMs, it is selected because CAM-BASE profiles are quite noisy for the operational time step when the vertical grid spacing is fine. For both simulation configurations, CAM-CLUBB properly represents cloud base and cloud top, and it reasonably simulates cloud amount and coverage. While cloud fraction suffers from a systematic negative bias near cloud base, $q_{1}$ simulated by CAM-CLUBB compares well with LES. As 


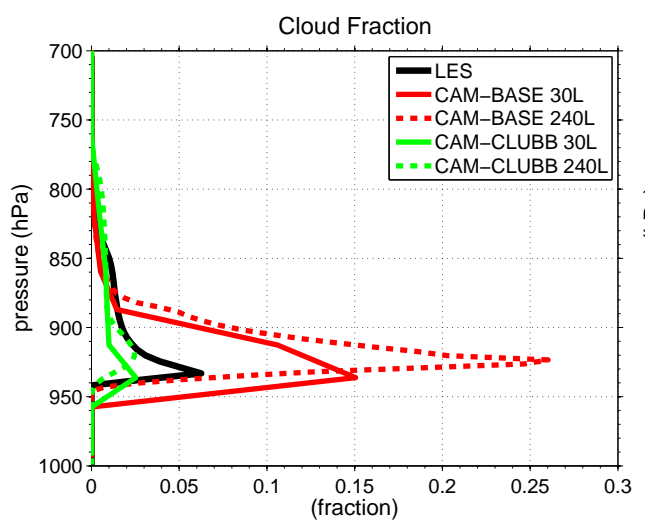

(a)

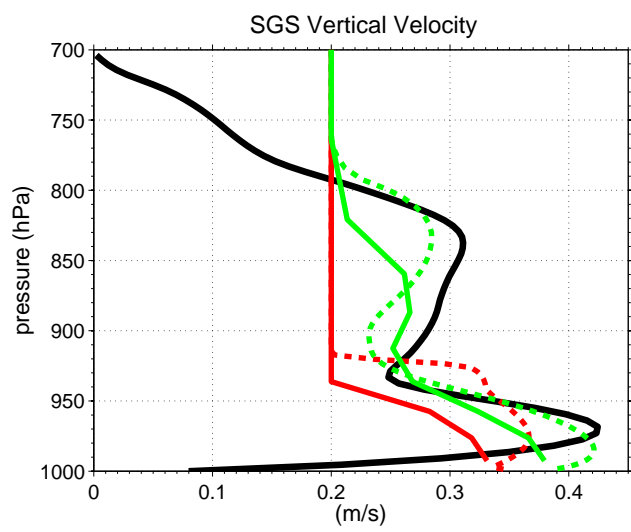

(c)

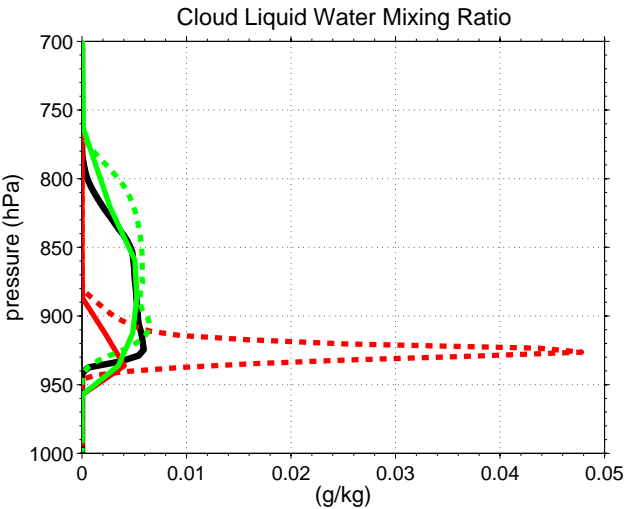

(b)

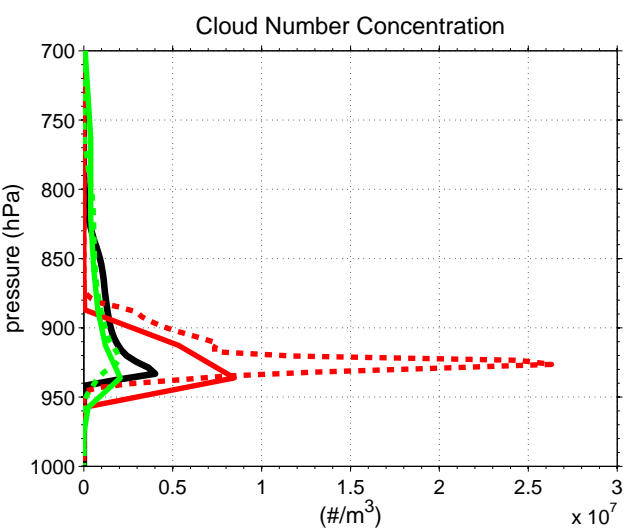

(d)

Fig. 2. Temporally averaged profiles of cloud fraction, cloud liquid water mixing ratio, SGS vertical velocity, and droplet number concentration from hours 4-6 of the simulation for the BOMEX case of non-precipitating trade-wind cumulus. LES is denoted by the solid black line, and SCAM simulations are denoted by the colored lines. Displayed here are simulations with 30 vertical levels (solid) and 240 vertical levels (dashed), both using a $\Delta t=300 \mathrm{~s}$ time step. Note that the minimum allowable SGS vertical velocity in CAM is $0.2 \mathrm{~ms} \mathrm{~s}^{-1}$.

suggested in Fig. 1, the robustness to changes in $\Delta z$ for this case is remarkable.

The simulated profiles of CAM-CLUBB appear to improve upon those simulated by CAM-BASE. While CAMBASE profiles of cloud fraction and $q_{1}$ are clearly representative of a trade-wind cumulus regime, both configurations of $\Delta z$ suffer from cloud fraction that is too large and cloud layers that are too shallow. Note that cloud fraction profiles are substantially different than those presented in Park and Bretherton (2009). This is because that study presented only the cumulus cloud fraction and neglected the stratiform contribution. Here we show the shallow convective plus stratiform cloud. One possible reason CAM-CLUBB simulates better cloud depth is that the vertical velocity distribution near cloud top is highly skewed (not shown), as only a few clouds of this regime reach these heights. In CLUBB, $\overline{w^{\prime 3}}$ is simulated well and hence the cloud macrophysical quantities benefit. CAM-BASE appears to simulate only the numerous shallow clouds that occur near cloud base. It is also important to mention that about half of the cloud produced near cloud base in CAM-BASE is from the UWMT scheme. As BOMEX is a purely trade-wind cumulus regime, one would expect the cloud to be represented solely by a shallow convection scheme. Since CLUBB is a unified parameterization of PBL and shallow convection that produces all cloud, this counter-intuitive behavior is avoided.

CAM-CLUBB's SGS vertical velocity profile (Fig. 2c) is improved when compared to CAM-BASE in both the sub-cloud mixed layer (roughly below $950 \mathrm{hPa}$ ) and in the cloud layer. The SGS vertical velocity in the cloud layer for CAM-BASE defaults to the minimum allowable value of $0.2 \mathrm{~m} \mathrm{~s}^{-1}$ for nearly all choices of $\Delta z$, suggesting that the UWSC scheme dominates at these levels, as one would expect. Therefore, the separate microphysics scheme within the UWSC parameterization is active in the cumulus layers. In contrast, since CAM-CLUBB utilizes the MG microphysics scheme for shallow cumulus as well as stratiform cloud, CAM-CLUBB's representation of $w^{\prime}$ and MG microphysics are available to activate aerosol and predict droplet concentration in a unified manner. 


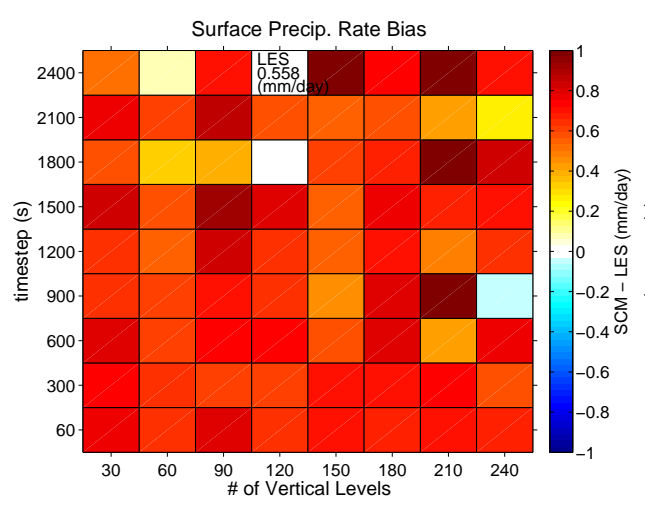

(a) CAM-BASE

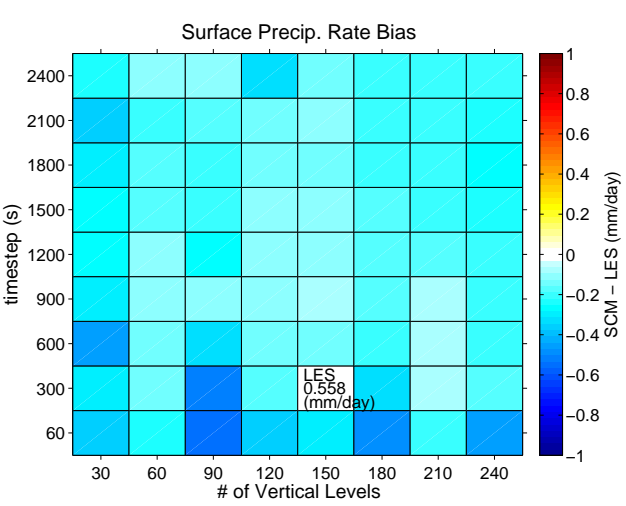

(b) CAM-CLUBB

Fig. 3. Same as Fig. 1, except for the bias of surface precipitation rates from the RICO case of precipitating trade-wind cumulus, averaged over hours 18-24.

The above presentation demonstrates that CAM-CLUBB produces reasonable results for the challenging regime of non-precipitating trade-wind cumulus clouds. The precipitating trade-wind cumulus case (RICO) was also performed with CAM-BASE and CAM-CLUBB. We found similar quality results for cloud fraction, $q_{1}, w^{\prime}$, and $N_{\mathrm{d}}$ (cloud number concentration) as displayed in the BOMEX case (not shown). Figure 3 illustrates both CAM-BASE and CAMCLUBB's ability in representing the light precipitation rates observed in this case for all combinations of $\Delta z$ and $\Delta t$. CAM-BASE has a tendency to overpredict the amount of rain that reaches the surface for this drizzling cumulus case for nearly all configurations of $\Delta z$ and $\Delta t$. Oftentimes this overestimation reaches a factor of three or four and is likely due to the CAM-BASE tendency to overpredict the liquid water and cloud amount. Most of the precipitation produced for CAM-BASE comes from the shallow convection microphysics scheme. CAM-CLUBB's results are more robust across the $\Delta t$ and $\Delta z$ spectrum and in better agreement with surface precipitation computed from the LES. The higher precipitation rates could also be a reason for the excessive shallowness of simulated cumulus layers in CAM-BASE.

\subsection{Continental cumulus}

The continental cumulus case that we investigate was observed over the ARM site in Oklahoma (Brown et al., 2002). The ARM case is qualitatively different than the maritime shallow cumulus case in that the ARM clouds are diurnally driven by time varying surface sensible heat fluxes, surface latent heat fluxes, and large-scale forcings as opposed to the quasi steady state reached in the BOMEX and RICO cases. Therefore, the ARM case allows us to test the timing of onset and decay of convection, in which clouds form over an initially clear convective boundary layer. The representation of $C$ and $q_{1}$ to changes in $\Delta z$ and $\Delta t$ for the ARM case exhibits similar behavior to that of Fig. 1 for both CAM-BASE and CAM-CLUBB and is therefore not displayed here.

CAM-CLUBB captures the timing of the onset/decay of cumulus clouds in response to surface forcing fairly accurately (Fig. 4). While cumulus initiation and decay are both delayed and the integrated cloud fraction is underestimated, the CAM-CLUBB configuration shows improvement when compared to CAM-BASE. CAM-BASE tends to predict too much fog early in the simulation and fails to dissipate the clouds near the end of the simulation in response to declining surface fluxes.

Overall, it appears that CAM-CLUBB can treat shallow cumulus (both maritime and continental) with fidelity. This is an encouraging result, as many recent studies (Gettelman et al., 2012; Medeiros et al., 2008) suggest that shallow cumulus convection contributes more strongly than stratocumulus clouds to climate feedbacks and sensitivity, due partly to the large area of the globe covered by shallow cumulus. However, while maritime stratocumulus clouds cover a much smaller portion of the global ocean, they are significant modulators of the Earth's radiation budget and increase the overall albedo (Hartmann et al., 1992) and must also be properly represented in GCMs. Therefore, the next test is to examine stratocumulus and transitional regimes.

\subsection{Cumulus under stratocumulus}

Transitional regimes are typically found downwind of classical maritime stratocumulus regimes and consist of tradewind cumulus underneath broken stratocumulus. Hence, this regime combines qualitative properties of both cumulus (i.e. BOMEX or RICO) as well as stratocumulus (i.e. DYCOMS2-RF01). It is important that any physics parameterization be able to represent this type of regime in order to achieve realistic global distributions of shortwave cloud forcing. We use the ATEX case as a benchmark for the stratocumulus over cumulus regime, which was studied in the LES 

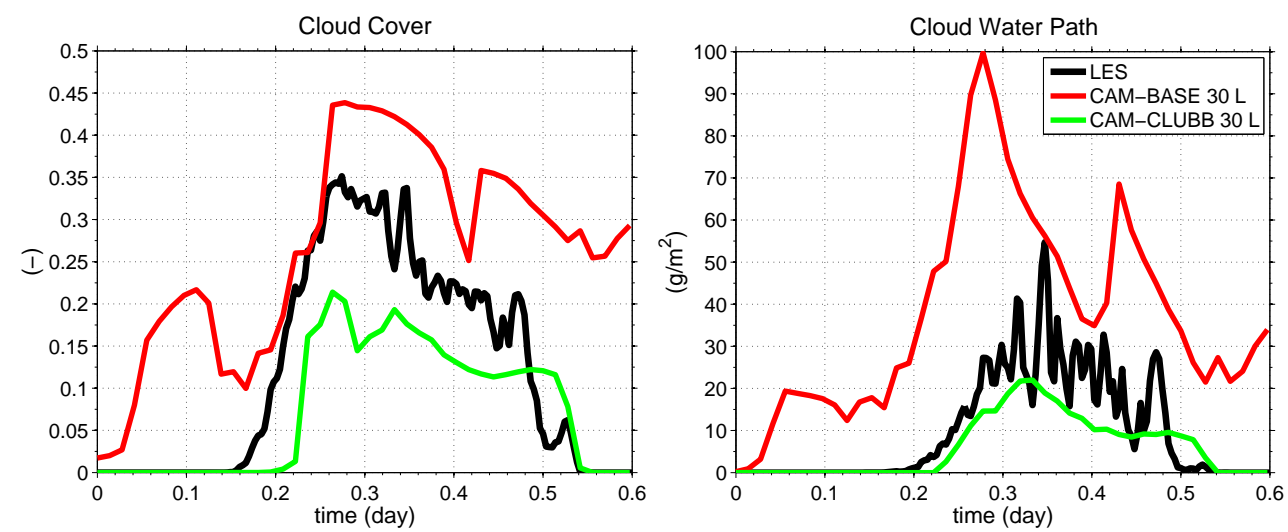

Fig. 4. Temporal evolution of the integrated low cloud fraction and liquid water path from the simulations of ARM case of continental shallow cumulus with 30 vertical levels and a 60-s time step.

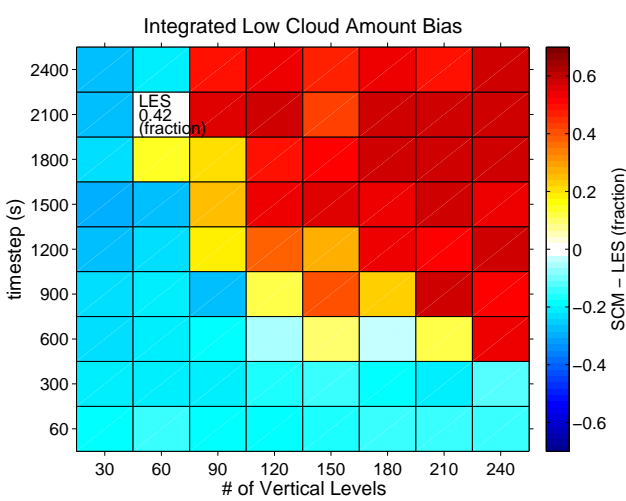

(a) CAM-BASE

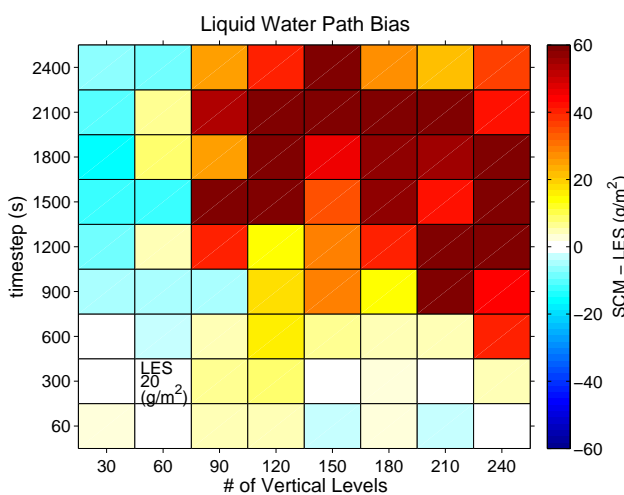

(c) CAM-BASE

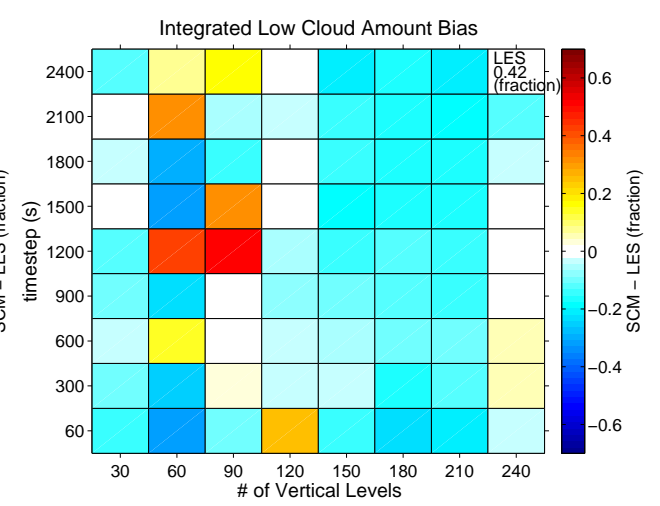

(b) CAM-CLUBB

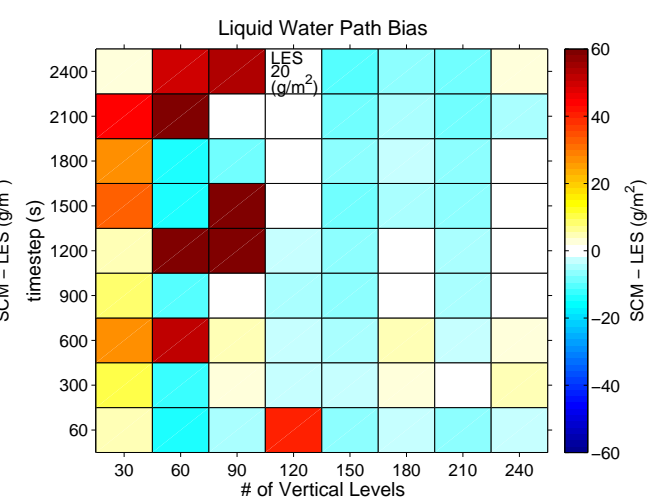

(d) CAM-CLUBB

Fig. 5. Same as Fig. 1 except averaged over hours $4-8$ of the simulation for the ATEX case of cumulus under stratocumulus.

intercomparison of Stevens et al. (2001). Each different LES in that study was able to capture the general characteristics of this regime; however, cloud amounts at inversion top varied greatly between codes (with vertically integrated cloud fractions ranging from 0.2 to 0.8 ).

Figure 5 displays the biases of CAM-BASE and CAMCLUBB for the integrated cloud amount and LWP for the
ATEX simulation for hours 4-8 of the simulation. Integrated cloud fraction amounts for CAM-CLUBB are clearly more sensitive for this case than they were for the shallow cumulus cases, with values ranging from 0.25 to 0.98 , depending on the simulation configuration and with less of a discernible pattern. However, CAM-CLUBB tends to have more instances where the integrated cloud fraction and LWP match 


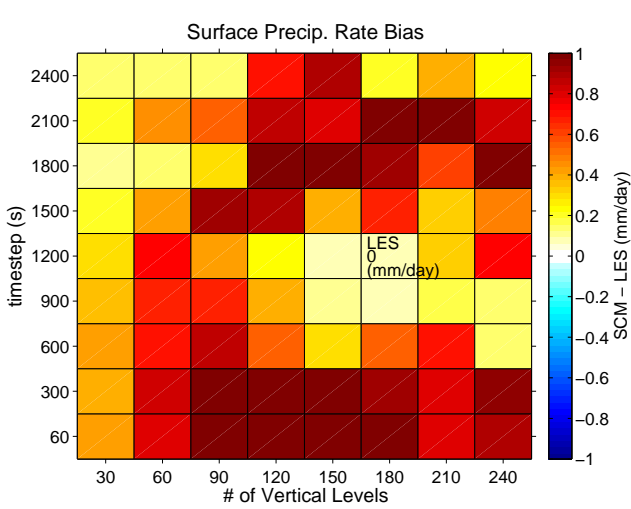

(a) CAM-BASE

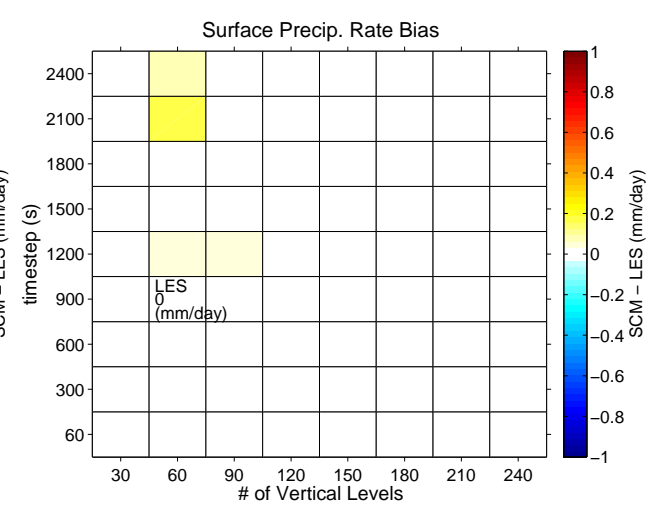

(b) CAM-CLUBB

Fig. 6. Same as Fig. 1, except for the bias of surface precipitation rates from the ATEX case of cumulus under stratocumulus, averaged over hours 4-8.

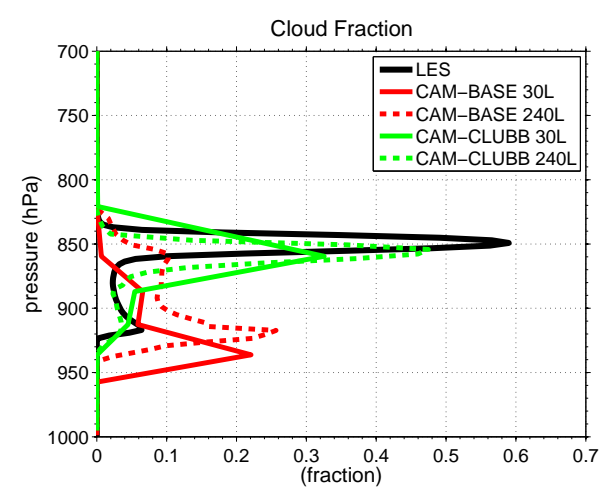

(a)

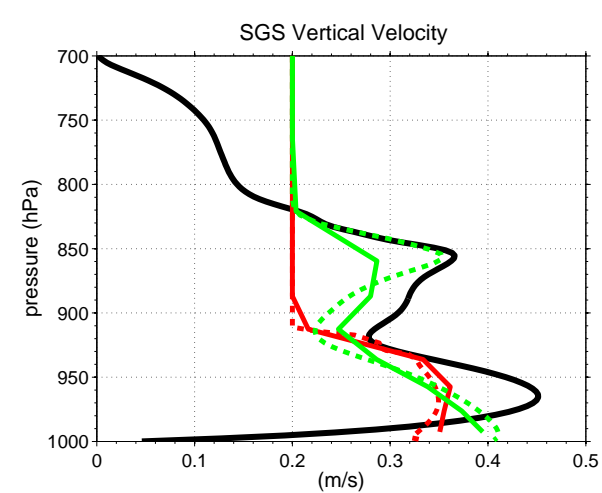

(c)

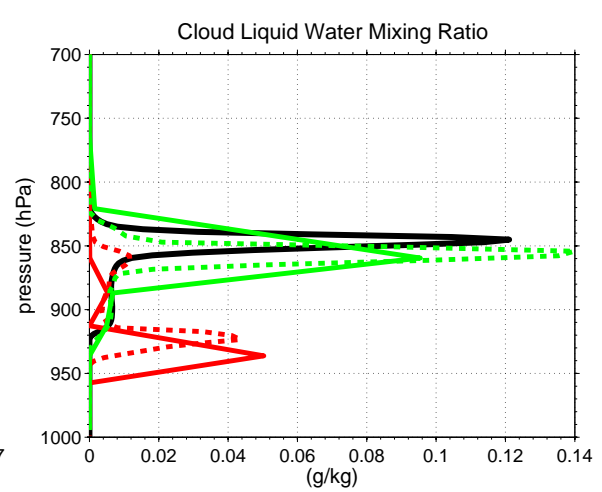

(b)

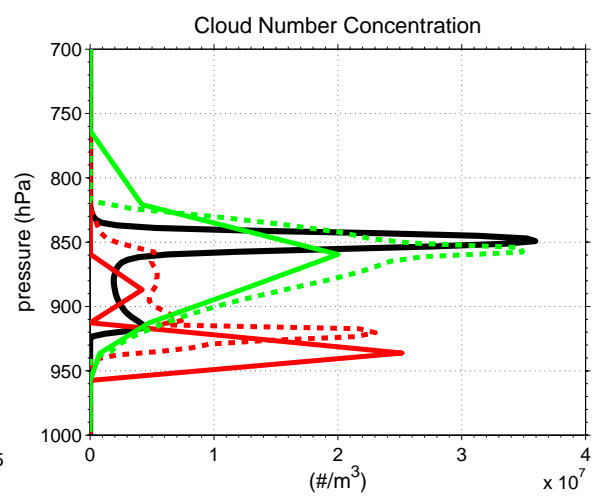

(d)

Fig. 7. Same as Fig. 2 except SCAM profiles represent ATEX simulations averaged over hours $4-8$, with fixed $\Delta t=300 \mathrm{~s}$ and 30 and 240 vertical levels.

LES $\left(0.42\right.$ and $20 \mathrm{~g} \mathrm{~m}^{-2}$ ), indicated by a clear or lightly hued cell, when compared to CAM-BASE. There are several instances where LWP and integrated cloud fraction resemble a purely stratocumulus $(\mathrm{Sc})$ regime for CAM-BASE, and a few instances of this for CAM-CLUBB. For CAMCLUBB it appears that this sensitivity is ameliorated for con- figurations using high vertical resolution, suggesting that this particular regime requires fine vertical grid spacing, as one would expect. Meanwhile, simulated LWP and integrated cloud fraction tend to degrade as vertical resolution becomes finer at longer time steps in the CAM-BASE configuration. 


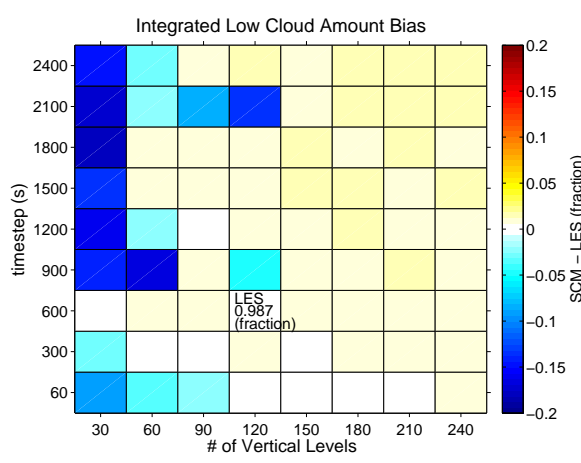

(a) CAM-BASE

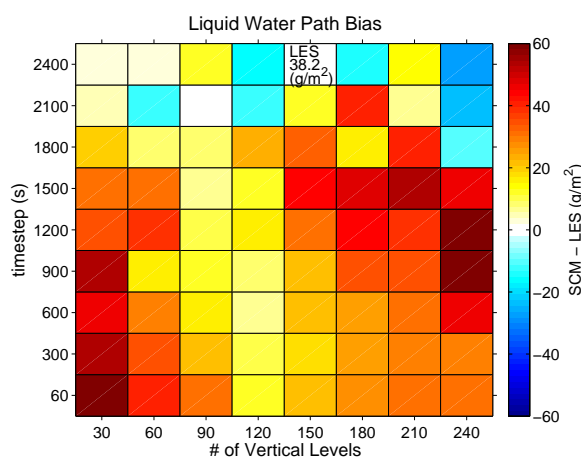

(c) CAM-BASE

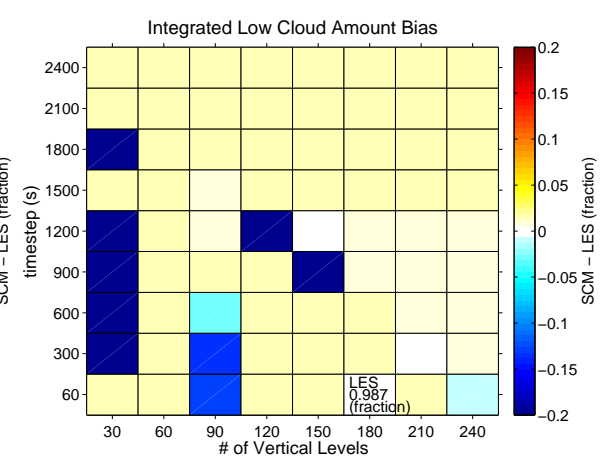

(b) CAM-CLUBB

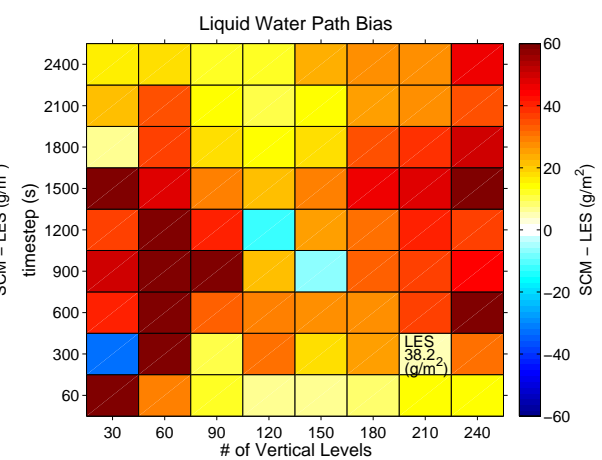

(d) CAM-CLUBB

Fig. 8. Same as Fig. 1 except averaged over hours 4-6 of the simulation for the DYCOMS2-RF01 case of maritime stratocumulus.

It is important to note that ATEX is an observationally non-precipitating case, although in these simulations we keep the microphysics turned on and allow precipitation in order to obtain a less idealized and more realistic simulation. For $94 \%$ of the simulations, CAM-CLUBB (Fig. 6) correctly predicts a zero surface precipitation rate whereas CAM-BASE produces large biases with precipitation rates of $0.4 \mathrm{~mm} \mathrm{day}^{-1}$ or higher (up to $2 \mathrm{mmday}^{-1}$ ) for $70 \%$ of the simulations. It appears that the majority of this precipitation is generated by the UWSC scheme.

Figure 7 displays the temporally averaged profiles of $C$ and $q_{1}$ for CAM-BASE and CAM-CLUBB between hours $4-8$ of the ATEX case for 30 and 240 levels and fixed $\Delta t=$ $300 \mathrm{~s}$. This figure shows that both configurations of CAMCLUBB are able to realistically represent the basic structure of the cumulus under stratocumulus regime. Although cloud top $C$ and $q_{1}$ are underestimated for the 30-level case, both CAM-CLUBB curves are within the range of the LES ensemble of Stevens et al. (2001). In addition, CAM-CLUBB profiles appear to be more realistic than CAM-BASE profiles, which tend to place the vertical maximums of $C$ and $q_{1}$ in the levels where cumulus, rather than stratocumulus, should be prevalent. This overrepresentation occurs because both the UWSC and UWMT schemes are active near cloud base. However, near Sc cloud top, nearly all cloud is produced from the Park stratiform macrophysics, as one would expect. Similar to results from BOMEX, CAM-CLUBB has a good representation of $w^{\prime}$ throughout the boundary layer; however, CAM-BASE underestimates $w^{\prime}$ throughout the entire cloud layer.

\subsection{Maritime stratocumulus}

The last regime we examine is a maritime stratocumulus regime, namely the DYCOMS2-RF01 (hereafter RF01) and DYCOMS2-RF02 (hereafter RF02) cases. RF01 is challenging case in which the stratocumulus cloud deck was observed to persist despite classical theories that suggested it should have dissipated over time (i.e. Randall, 1980). RF02 is a marine Sc case that was observed to contain drizzle (Ackerman et al., 2009). The standard GCSS case setup for RF01 (Stevens et al., 2005) is a 6-h nocturnal simulation with prescribed and constant surface and latent heat fluxes. The setup we use is identical to that described in Stevens et al. (2005), except that we extend the case to four days with a diurnal cycle in radiative forcing. The GCSS averaging interval is still examined for direct comparison with LES for CAM-BASE and CAM-CLUBB. However, we expect the marine $\mathrm{Sc}$ to persist through the four-day period.

First we examine the sensitivity of CAM-BASE and CAM-CLUBB to $\Delta z$ and $\Delta t$ for the GCSS averaging interval of hours 4-6 of the simulation. Figure 8 displays the biases in integrated low cloud amount (top row) and 


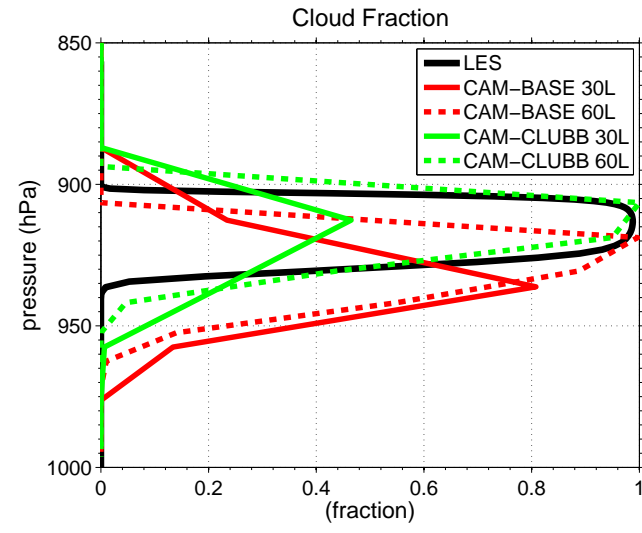

(a)

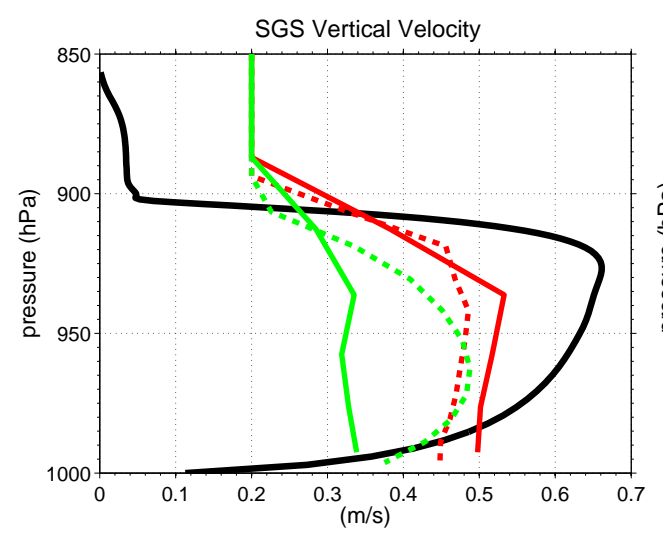

(c)

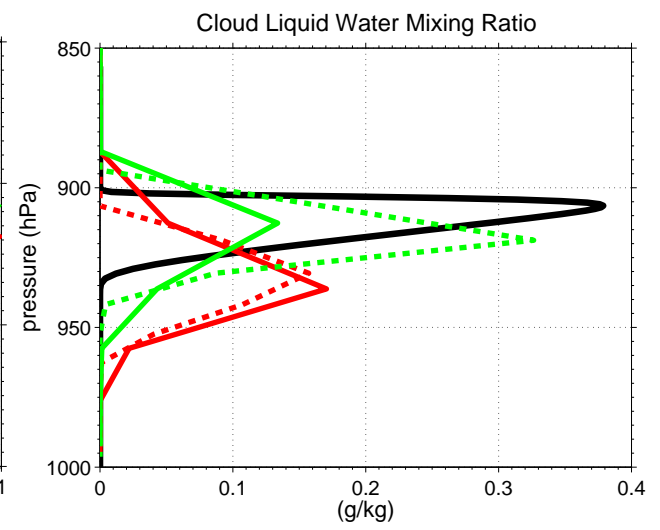

(b)

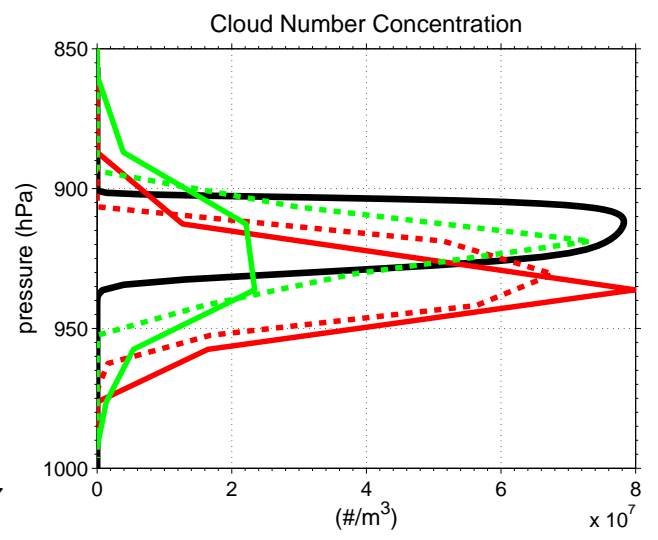

(d)

Fig. 9. Same as Fig. 2 except SCAM profiles represent DYCOMS2-RF01 simulations averaged over hours 4-6, with fixed 30 and 60 vertical levels and $\Delta t=1800 \mathrm{~s}$.

LWP (bottom row). Unlike the results for the convective cumulus cases, results between the two model configurations do not differ greatly. This is in agreement with Bretherton and Park (2009), who showed that the UWMT scheme is robust to changes in $\Delta z$ for marine stratocumulus. LES suggests an integrated low cloud amount $\sim 1$, and it appears that both CAM configurations can produce solid cloud cover for most $\Delta z$ and $\Delta t$ configurations. The largest (negative) biases for both CAM-BASE and CAM-CLUBB occur for the operational 30-level configurations. Upon examination of the LWP, it is evident that almost all simulation configurations overestimate this quantity. This is surprising since one might expect parameterizations to underestimate cloud water for RF01 due to the very dry air in the free troposphere. However, this positive bias appears to be due to the tendency of both CAM-BASE and CLUBB parameterizations to produce cloud layers that are slightly too thick compared to LES, which is consistent with the findings of Zhu et al. (2005). However, bias patterns and magnitudes are similar for CAMBASE and CAM-CLUBB.
Temporally averaged profiles of CAM-BASE and CAMCLUBB can be viewed in Fig. 9 over the GCSS averaging interval. In this figure the configurations use the operational time step of $\Delta t=1800 \mathrm{~s}$ for 30 and 60 levels. While CAMCLUBB predicts less cloud coverage for the operational 30 grid level when compared to CAM-BASE, the levels of cloud base and cloud top are better represented for CAM-CLUBB for both $\Delta z$ configurations. For the case of 60 vertical levels, CAM-CLUBB has better agreement with LES for $C$ and $q_{1}$, both in terms of vertical placement and magnitude. While it is evident that CAM-CLUBB is more sensitive to changes in $\Delta z$ for this case, the improvement for the 60 level case over CAM-BASE is encouraging.

In terms of SGS vertical velocity, CAM-CLUBB underestimates $w^{\prime}$ for the 30-level case. This occurs probably because there is a lack of cloud cover and mass compared to LES, which acts to reduce cloud-top feedbacks that are necessary to maintain an adequately turbulent mixed layer. Along with SGS vertical velocity, accurate representation of $N_{\mathrm{d}}$ is also required to represent aerosol indirect effects. In both simulations $N_{\mathrm{d}}$ is predicted by the MG microphysics 


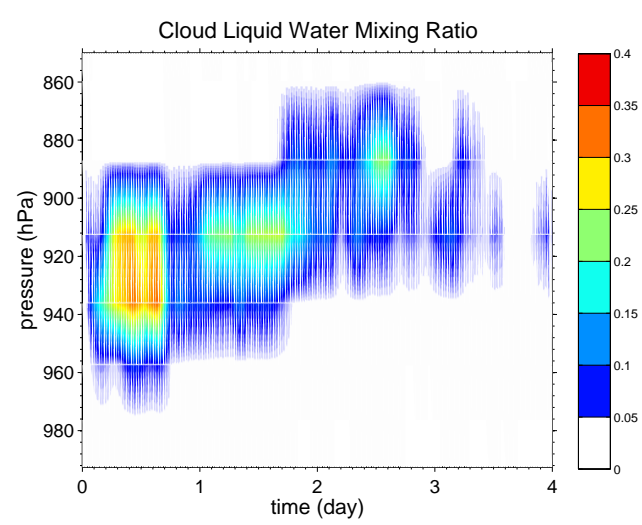

(a) CAM-BASE

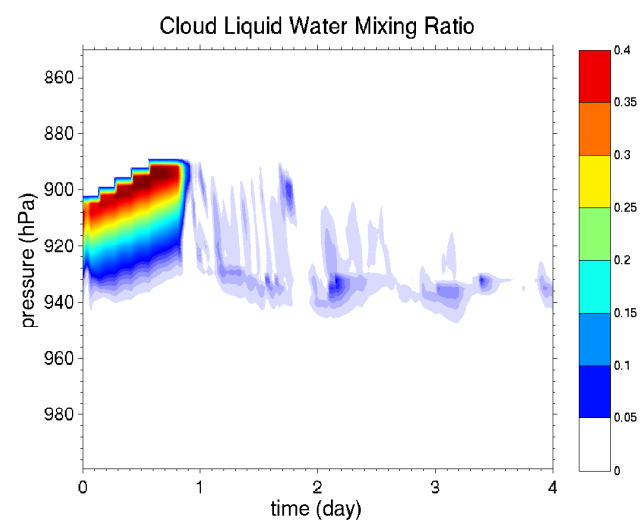

(c) CAM-BASE

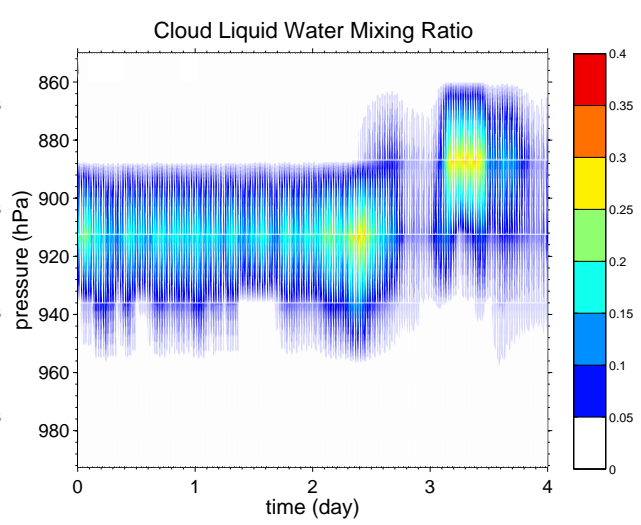

(b) CAM-CLUBB

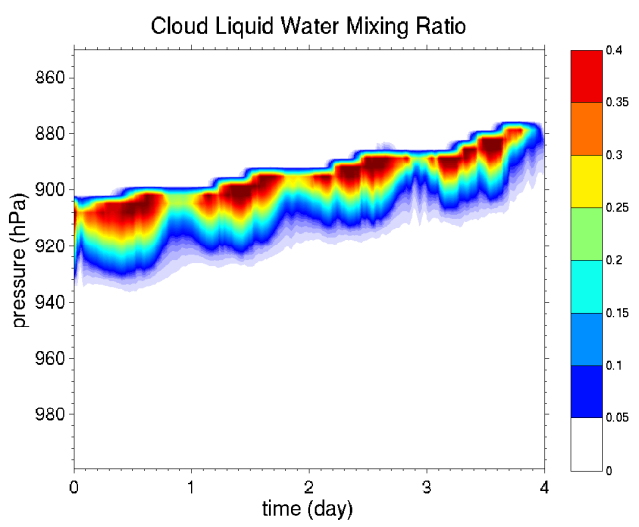

(d) CAM-CLUBB

Fig. 10. Evolution of the cloud liquid water mixing ratio $\left(\mathrm{g} \mathrm{kg}^{-1}\right)$ for CAM-BASE (a, c) and CAM-CLUBB (b, d) for the four-day simulation of DYCOMS2-RF01 using 30 vertical levels and $\Delta t=1800 \mathrm{~s}(\mathbf{a}, \mathbf{b})$ and 240 vertical levels and $\Delta t=60 \mathrm{~s}(\mathbf{c}, \mathbf{d})$.

scheme, and both CAM-BASE and CAM-CLUBB simulations can adequately represent this quantity. However, CAMCLUBB underestimates $N_{\mathrm{d}}$ using 30 levels, due to the underestimation of cloud mass as well as $w^{\prime}$. Overall, the simulations of RF01 for both CAM-BASE and CAM-CLUBB do not vary greatly during the GCSS averaging interval.

Next we test whether either configuration can maintain the cloud through the entire four-day period, including the daytime periods when the cloud is expected to thin due to incoming shortwave radiation and decouple from the wellmixed layer below (Krueger et al., 1995). The cloud deck is expected to regain its optical thickness during the nighttime when longwave radiational cooling at cloud top becomes the dominate source of turbulence. This can be thought of as a more "real world" test for GCM parameterization.

Figure 10 displays the evolution of the cloud water mixing ratio for both CAM-BASE and CAM-CLUBB for the entire four-day simulation. We test an operational configuration with 30 levels and $\Delta t=1800 \mathrm{~s}$ (top row) and a high-resolution configuration with 240 levels and $\Delta t=$ $60 \mathrm{~s}$. For both configurations, CAM-BASE tends to dissipate the cloud, gradually for the coarse-resolution simulation and abruptly for the high-resolution simulation. Upon investigation, it appears that, during the day time period, once decoupling of the boundary layer occurs, the UWSC takes over the UWMT scheme and the Sc deck undergoes a transition to a more cumulus-like state. This is consistent with forecasts of stratocumulus in Medeiros et al. (2012). CAM-CLUBB, on the other hand, maintains the cloud in both configurations for the entire four day period, with a diurnal cycle present in both grid simulations. Note that the strong oscillations for both CAM-BASE and CAM-CLUBB in the 30-level configuration appear to be related to the rather coarse time step as these oscillations do not appear in the 30-level configuration with $\Delta t=60 \mathrm{~s}$ (not shown).

The second marine Sc case we investigate is the RF02 case, which is set up in SCAM exactly as described in Ackerman et al. (2009). This case is often thought to be easier to simulate than RF01 because the inversion for both temperature and moisture is not quite as sharp above cloud top. Indeed, intercomparison agreement among LES is better for RF02 (Ackerman et al., 2009) than for RF01 (Stevens et al., 2005). Unlike the RF01 case, we only simulate this case over the 6-h GCSS interval. 


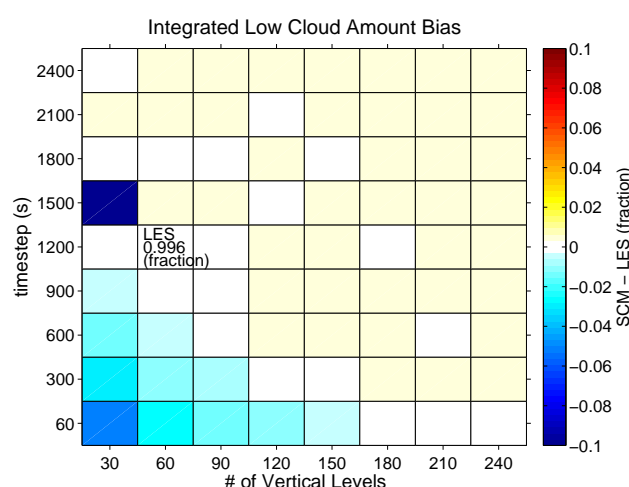

(a) CAM-BASE

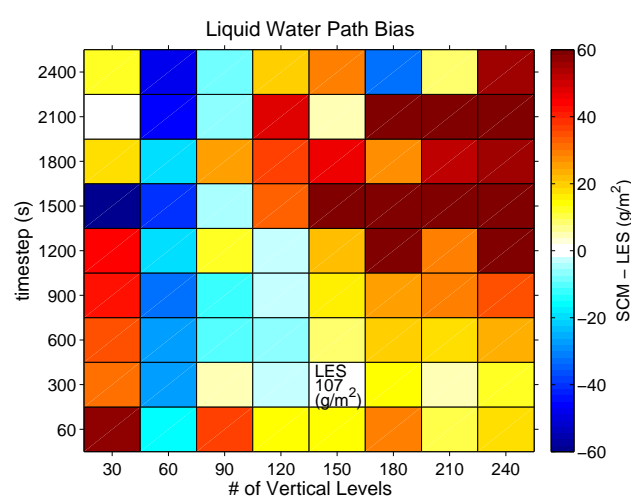

(c) CAM-BASE

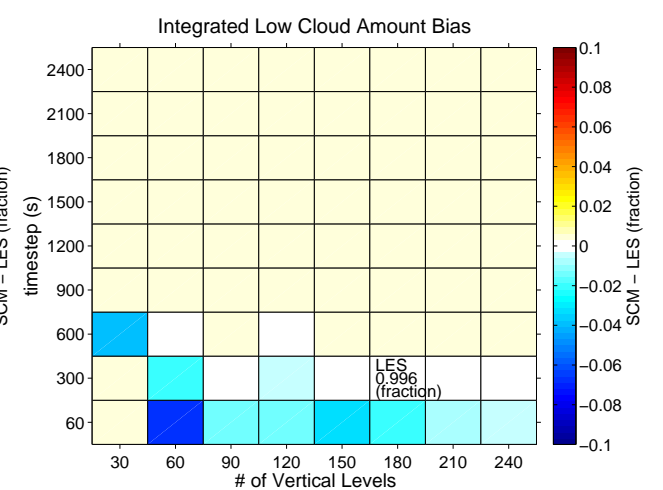

(b) CAM-CLUBB

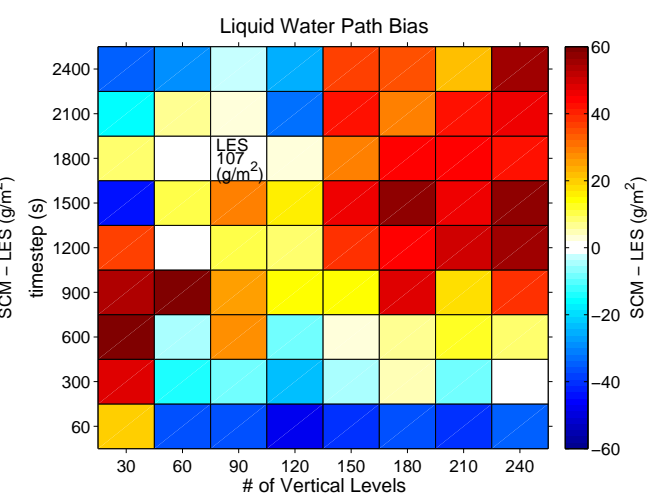

(d) CAM-CLUBB

Fig. 11. Same as Fig. 1 except averaged over hours 4-6 of the simulation for the DYCOMS2-RF02 case of maritime stratocumulus.

While CAM-CLUBB's sensitivity of integrated cloud fraction to changes in $\Delta z$ and $\Delta t$ is decidedly more robust for RF02 compared to RF01 (Fig. 11), LWP has more variation for both model configurations. This is somewhat surprising and suggests that the CAM microphysics scheme could be playing more of a role here than in the non-precipitating RF01 case. Whereas LES suggests a LWP of $107 \mathrm{~g} \mathrm{~m}^{-2}$, more often than not CAM-BASE and CAM-CLUBB either underestimate or overestimate this value. However, the minimum LWP values by both model configurations $\left(\sim 60 \mathrm{~g} \mathrm{~m}^{-2}\right)$ are still representative of a marine stratocumulus regime. It should be noted that, for both RF01 and RF02, the sensitivities of surface precipitation rates to $\Delta t$ and $\Delta z$ are nearly identical for CAM-BASE and CAM-CLUBB. Therefore, an analogous plot to Fig. 3 is not shown for these cases.

Figure 12 displays the temporally averaged profiles over hours 4-6 of cloud fraction, $q_{1}, w^{\prime}$, and $N_{\mathrm{d}}$ for CAM-BASE and CAM-CLUBB for the DYCOMS2-RF02 case. The time step in these profiles is fixed to $\Delta t=300 \mathrm{~s}$ with the 30 and 240 vertical levels. In terms of $C$ and $q_{1}$, there is very little difference seen between CAM-BASE and CAM-CLUBB.

Overall, the differences seen in the stratocumulus cases (RF01 and RF02) between CAM-BASE and CAMCLUBB are smaller than the differences seen in cumulus cases or transitional ATEX case. This is especially clear when evaluating the GCSS averaging intervals for nocturnal stratocumulus. However, when a diurnal cycle is considered, it appears that CAM-CLUBB can maintain the cloud deck through the simulation more successfully than CAM-BASE, owing to interactions between the separate turbulence and shallow convection schemes.

\section{Conclusions}

This paper describes the coupling of CAM with a relatively new parameterization, CLUBB. CLUBB is a higherorder turbulence closure based upon an assumed doubleGaussian probability density function (PDF). The assumed PDF is used to compute many unclosed turbulent moments and cloud macrophysical quantities, such as cloud fraction and cloud water mixing ratio. This "unified" closure is inherently different than traditional parameterizations used in GCMs as it is responsible for providing the tendencies of turbulent mixing from the PBL, shallow convection, and cloud macrophysics in one parameterization call rather than splitting these duties among several different parameterizations that may or may not be consistent with one another. In addition, CLUBB drives a single microphysics scheme (MG) for 


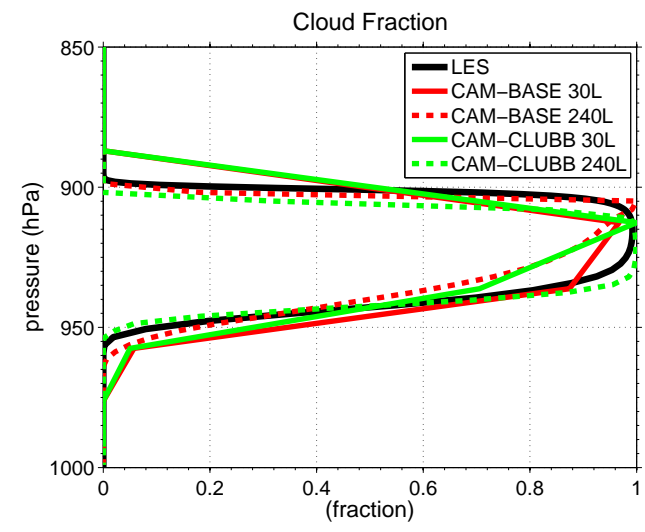

(a)

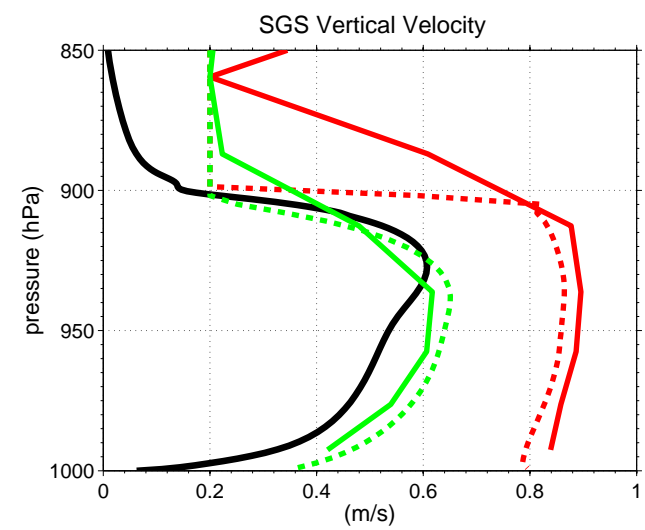

(c)

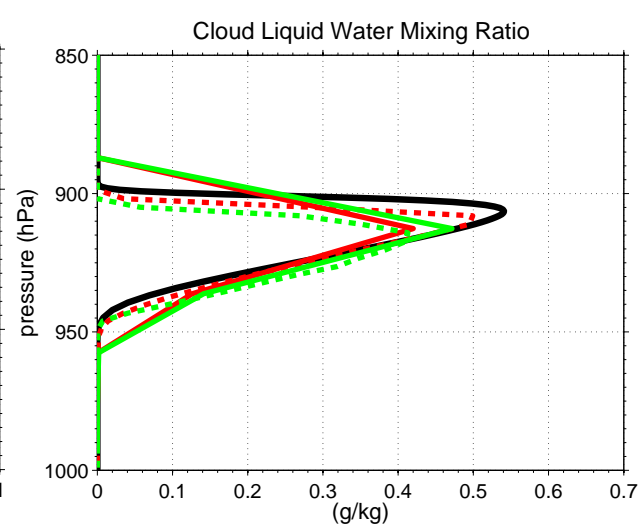

(b)

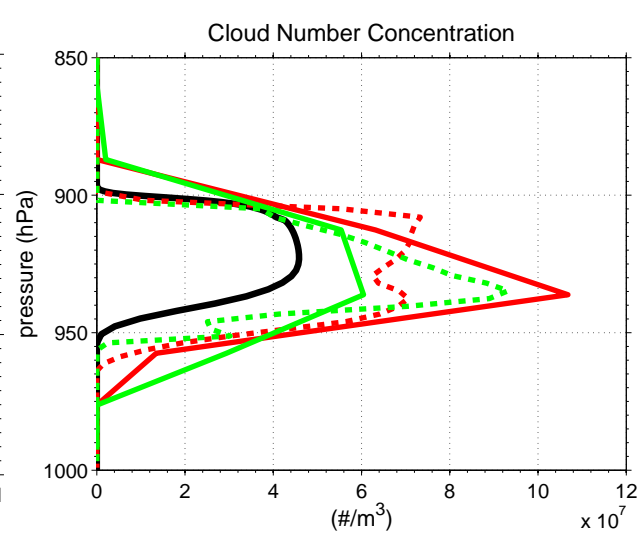

(d)

Fig. 12. Same as Fig. 2 except SCAM profiles represent DYCOMS2-RF02 simulations averaged over hours 4-6, with fixed 30 and 240 vertical levels and $\Delta t=300 \mathrm{~s}$.

both shallow convection and stratiform cloud, whereas the shallow convection scheme in CAM-BASE has its own treatment of microphysics. Therefore, CLUBB allows for a more unified treatment of cloud-aerosol interactions.

For the coupling of CAM with CLUBB described in this paper, CLUBB replaces the University of Washington Moist Turbulence (UWMT, Bretherton et al., 2009) scheme, the University of Washington Shallow Convection (UWSC; Park and Bretherton, 2009) scheme, and the cloud macrophysics scheme in CAM5. The physics that are retained in CAMCLUBB include the deep convection (Zhang and McFarlane, 1995; Neale et al., 2008; Richter and Rasch, 2008), aerosol (Liu et al., 2011) and microphysics schemes (Morrison and Gettelman, 2008). In the CAM-CLUBB configuration, the SGS vertical velocity $\left(w^{\prime}\right)$ is computed from the predicted $\overline{w^{\prime 2}}$ and is passed to the aerosol activation scheme.

Results from single-column CAM (SCAM) testing were presented in this paper for a wide range of boundary layer regimes. These include shallow cumulus, transitional regimes, as well as maritime stratocumulus regimes. To test the robustness of the models, a direct comparison between
CAM-BASE and CAM-CLUBB is performed for a variety of temporal and vertical resolutions, with the main model time step, $\Delta t$, varying from $60 \mathrm{~s}$ to $2400 \mathrm{~s}$ and $\Delta z$ varying from configurations utilizing 30 levels to 240 levels. The operational configuration of CAM consists of $\Delta t=1800 \mathrm{~s}$ and 30 vertical levels. It is important to note that, in this study, CLUBB is subcycled with a time step of $5 \mathrm{~min}$, whereas CAM-BASE's cloud parameterizations are not subcycled but rather use the full model time step of $1800 \mathrm{~s}$. However, using CLUBB with a time step of $300 \mathrm{~s}$ increases the overall computational cost by only $4 \%$ relative to the standard configuration of CAM-BASE, in which a time step of $1800 \mathrm{~s}$ is used for all parameterizations. CLUBB's subcycled time step is analogous to the iteration loops in the CAM-BASE physics options that are shut off in CAM-CLUBB. Furthermore, experiments suggest that increasing the number of iteration cycles for CAM-BASE parameterizations does not necessarily lead to better results at coarse host model time steps.

For cases of shallow cumulus convection (i.e. BOMEX, RICO, and ARM), it appears that CAM-CLUBB has advantages compared to CAM-BASE. For all shallow cumulus 
cases that we tested, CAM-CLUBB is more robust to changes in $\Delta t$ and $\Delta z$ while providing results that are in better agreement with LES. CAM-BASE tends to produce cumulus layers that are too shallow and cloudy, likely due to limitations of the mass flux scheme to represent the highly skewed vertical velocity statistics of this regime. In contrast, CAM-CLUBB predicts $\overline{w^{\prime 3}}$ and hence vertical velocity skewness, which allows for more accurate representation of this regime, with SGS vertical velocity values in the cloud layer that highly resemble those from LES. In addition, surface precipitation rate for CAM-CLUBB, which relies on the MG microphysics for this regime, is in better agreement with LES and observations for the RICO case. In the CAM-BASE simulations, the UWMT moist turbulence scheme is responsible for contributing to the overly cloudy layers in the shallow cumulus regime. Because CLUBB is a unified parameterization of shallow cumulus and the PBL, it avoids the problem of the stratiform scheme contributing undesirably to cumulus simulations. CAM-CLUBB also has the ability to represent a realistic cumulus under stratocumulus boundary layer, as shown by comparisons to LES in the ATEX case. This result is especially encouraging as Kay et al. (2012) show negative low cloud biases for CAM4 and CAM5 in tropical transition regions.

Results from the GCSS DYCOMS2-RF01 (RF01) and DYCOMS2-RF02 (RF02) cases of stratocumulus show fewer differences between CAM-BASE and CAM-CLUBB compared to the shallow cumulus cases. However, it is important to note that running RF01 for four days with a diurnal cycle shows that CAM-CLUBB can maintain the stratocumulus cloud better through this period compared to CAMBASE for most $\Delta t$ and $\Delta z$ configurations. During the latter days of the four-day RF01 simulation for CAM-BASE, the shallow convective scheme becomes active during the daytime hours, which more often than not leads to entrainment rates that are too high and an excessive depletion of liquid water.

The results from these cases suggest that the configuration of CAM using CLUBB is more unified in the sense that it can represent both shallow cumulus and marine Sc with good agreement with LES. In addition, the results suggest promise for representation of indirect aerosol effects because CAM-CLUBB represents the SGS vertical velocity and cloud droplet concentration with fidelity. In addition, CAM-CLUBB employs the MG microphysics scheme for both shallow cumulus and stratocumulus, whereas CAMBASE uses separate microphysics schemes for these two regimes. Using a single microphysics scheme allows for a more consistent treatment of microphysics and aerosol interactions. The robustness of CAM-CLUBB, as well as the ability to use the same microphysics scheme for all of the cases tested, is encouraging. The results from the tradecumulus cases are especially encouraging as recent studies (Gettelman et al., 2012; Mederios et al., 2008) find that shallow cumulus regimes, with their widespread coverage across the globe, contribute most strongly to climate sensitivity and feedbacks.

Although these single-column results are promising, the key test will involve running CAM-CLUBB globally. The hope is that the same caliber results found in these singlecolumn simulations will transfer over to multi-year and decadal global simulations. For this study, none of the tunable parameters within CLUBB were modified. However, tuning may become necessary in global simulations in order to achieve radiative balance or realistic distributions of cloud radiation forcing, for example. Future work will involve investigating the aerosol indirect effect, climate sensitivity, and feedbacks of CAM-CLUBB as compared to CAMBASE as well as other GCMs. One can take advantage of the SGS variability provided by CLUBB to generate subcolumns (Pincus et al., 2006) and thereby avoid the use of "maximum-random" cloud overlap assumptions in both microphysics and radiation parameterizations. In addition, as mentioned throughout this paper, one can take advantage of CLUBB's SGS PDF information for treatment of microphysics and aerosol processes. For example, one can use the variance of liquid water and covariance of liquid water and rain water for computation of autoconversion and accretion process rates. In addition, we can integrate over the PDF for vertical velocity for the computation of aerosol activation (Ghan et al., 1997). These treatments will be explored in future versions of CAM-CLUBB.

Acknowledgements. P. A. Bogenschutz is supported by National Science Foundation grant number 0968657. The National Center for Atmospheric Research is sponsored by the United States National Science Foundation. The authors are grateful to Brian Medeiros, Jennifer E. Kay, Steven J. Ghan, and an anonymous reviewer for reading and suggesting improvements to this manuscript.

Edited by: H. Garny

\section{References}

Ackerman, A. S., VanZanten, M. C., Stevens, B., Savic-Jovcic, V., Bretherton, C. S., Chlond, A., Golaz, J.-C., Jiang, H., Khairoutdinov, M., Krueger, S. K., Lewellen, D. C., Lock, A., Moeng, C.-H., Nakamura, K., Petters, M. D., Snider, J. R., Weinbrecht, S., and Zulauf, M.: Large-eddy simulations of a drizzling, stratocumulus-topped marine boundary layer, Mon. Weather Rev., 137, 1083-1110, 2009.

Bogenschutz, P. and Krueger, S. K.: Improved boundary layer cloud simulations in cloud resolving models with a simple turbulence closure, submitted, 2012.

Bogenschutz, P., Krueger, S. K., and Khairoutdinov, M.: Assumed probability density functions fo shallow and deep convection, J. Adv. Model. Earth Syst., 2, 10, doi:10.3894/JAMES.2010.2.10, 2010.

Bony, S. and Dufresne, J.-L.: Marine boundary layer clouds at the heart of tropical cloud feedback uncertainties in climate model, 
Geophys. Res. Lett., 32, L20806, doi:10.1029/2005GL023851, 2005.

Bretherton, C. S. and Park, S.: A new moist turbulence parameterization in the community atmosphere model, J. Climate, 22, 3422-3448, 2009.

Brown, A. R., Cederwall, R. T., Chlond, A., Duynkerke, P. G., Golaz, J.-C., Khairoutdinov, M., Lewellen, D. C., Lock, A. P., Macvean, M. K., Moeng, C.-H., Neggers, R. A. J., Siebesma, A. P., and Stevens, B.: Large-eddy simulation of the diurnal cycle of shallow cumulus convection over land, Q. J. R. Meteorol. Soc., 128, 1075-1094, 2002.

Cheng, A. and Xu, K.-M.: Simulation of shallow cumuli and their transition to deep convective clouds by cloud-resolving models with different third-order turbulence closures, Q. J. R. Meteorol. Soc. doi:10.1256/qj.05.29, 2006.

Cheng, A. and $\mathrm{Xu}, \mathrm{K} .-\mathrm{M} .:$ Improved low-cloud simulation from a multiscale modeling framework with a third-order turbulence closure in its cloud resolving model component, J. Geophys. Res., 115, D14101, doi:10.1029/2010JD015362, 2011.

Donner, L. J., Wyman, B. L., Hemler, R. S, Horowitz, L. W., Ming, Y., Zhao, M., Golaz, J.-C., Ginoux, P., Lin, S.-J., Schwarzkopf, M. D., Austin, J., Alaka, G., Cooke, W. F., Delworth, T. L., Freidenreich, S. M., Gordon, C. T., Griffies, S. M., Held, I. M., Hurlin, W. J., Klein, S. A., Knutson, T. R., Langenhorst, A. R., Lee, H. C., Lin, Y., Magi, B. I., Malyshev, S. L., Milly, P. C. D., Naik, V., Nath, M. J., Pincus, R., Ploshay, J. J., Ramaswamy, V., Seman, C. J., Shevliakova, E., Sirutis, J. J., Stern, W. F., Stouffer, R. J., Wilson R. J., Winton, M., Wittenberg, A. T., and Zeng, F: The dynamical core, physical parameterizations, and basic simulation characteristics of the atmospheric component AM3 of the GFDL Global Coupled Model CM3, J. Climate, 24, 3484-3519, 2011.

Gettelman, A., Liu, X., Ghan, S. J., Morrison, H., Park, S., Conley, A. J., Klein, S. A., Boyle, J., Mitchell, D. L., and Li, J.-L. F.: Global simulations of ice nucleation and ice supersaturation with an improved cloud scheme in the community atmosphere model, J. Geophys. Res., 115, D18216, doi:10.1029/2009JD013797, 2010.

Gettelman, A., Kay, J. E., and Shell, K. M.: The evolution of climate sensitivity and climate feedbacks in the community atmosphere model, J. Climate, 25, 1453-1469, 2012.

Golaz, J.-C., Larson, V. E., and Cotton, W. R.: A pdf-based model for boundary layer clouds part I: method and model description, J. Atmos. Sci., 59, 3540-3551, 2002.

Ghan, S. J., Leung, L., R., Easter, R., C., and Abdul-Razzak, H.: Prediction of cloud droplet number in a general circulation model, J. Geophys. Res., 102, 21 777-21 794, 1997.

Golaz, J.-C., Wang, S., Doyle, J. D., Schmidt, J. M.: Model evaluation and analysis of second and third moment vertical velocity budgets, Bound.-Lay. Meteorol., 116, 487-517, 2005.

Golaz, J.-C., Larson, V. E., Hansen, J. A., Schanen, D. P., Griffin, B. M.: Elucidating model inadequacies in a cloud parameterization by use of an ensemble-based calibration framework, Mon. Weather Rev., 135, 4077-4096, 2007.

Guo, H., Golaz, J.-C., Donner, L. J., Larson, V. E., Schanen, D. P., and Griffin, B. M.: Multi-variate probability density functions with dynamics for cloud droplet activation in large-scale models: single column tests, Geosci. Model Dev., 3, 475-486, doi:10.5194/gmd-3-475-2010, 2010.
Hack, J. J.: Parameterization of moist convection in the National Center for Atmospheric Research Community climate Model (CCM2), J. Geophys. Res., 99, 5551-5568, 2004.

Hartmann, D. L., Ockert-Bell, M. E., and Michelsen, M. L.: The Effect of cloud type on Earth's energy balance: global analysis, J. Climate, 5, 1281-1304, 1992.

Heintzenberg, J. and Charlson, R. J.: Clouds in the perturbed climate system, MIT press, 2009.

Holtslag, A. A. M. and Boville, B. A.: Local versus nonlocal boundary layer diffusion in a global climate model, J. Climate, 6, 18251842, 1993.

Kay, J. E., Hillman, B., Klein, S., Zhang, Y., Medeiros, B., Gettelman, A., Pincus, R., Eaton, B., Marchand, R., and Ackerman, T.: Exposing global cloud biases in the Community Atmosphere Model (CAM) using satellite observations and their corresponding instrument simulators, J. Climate, J. Climate, 25, 5190-5207, doi:10.1175/JCLI-D-11-00469.1, 2012.

Khairoutdinov, M. F. and Randall, D. A.: Cloud resolving modeling of the ARM summer 1997 IOP: model formulations, results, uncertainties, and sensitivities, J. Atmos. Sci., 60, 607-625, 2003.

Krueger, S. K., McLean, G. T., and Fu, Q.: Numerical simulation of the stratus-to-cumulus transition in the subtropical marine boundary layer, part I: boundary-layer structure, J. Atmos. Sci., 52, 2839-2850, 1995.

Lappen, C.-L. and Randall, D. A.: Toward a unified parameterization of the boundary layer and moist convection, part I: a new type of mass flux model, Atmos. Sci., 58, 2021-2035, 2001.

Larson, V. E., Golaz, J.-C., and Cotton, W. R.: Small-scale and mesoscale variability in cloudy boundary layers: joint probability density functions, J. Atmos. Sci., 59, 3519-3539, 2002.

Larson, V. E. and Golaz, J.-C.: Using probability density functions to derive consistent closure relationships among higher-order moments, Mon. Weather Rev., 133, 1023-1042, 2005.

Larson, V. E., Schanen, D. P., Wang, M., Ovchinnikov, M., and Ghan, S.: PDF parameterization of boundary layer clouds in models with horizontal grid spacings from 2 to $16 \mathrm{~km}$, Mon. Weather Rev., 140, 285-306, 2012.

Liu, X., Easter, R. C., Ghan, S. J., Zaveri, R., Rasch, P., Shi, X., Lamarque, J.-F., Gettelman, A., Morrison, H., Vitt, F., Conley, A., Park, S., Neale, R., Hannay, C., Ekman, A. M. L., Hess, P., Mahowald, N., Collins, W., Iacono, M. J., Bretherton, C. S., Flanner, M. G., and Mitchell, D.: Toward a minimal representation of aerosols in climate models: description and evaluation in the Community Atmosphere Model CAM5, Geosci. Model Dev., 5, 709-739, doi:10.5194/gmd-5-709-2012, 2012.

Lock, A. P., Brown, A. R., Bush, M. R., Martin, G. M., and Smith, R. N. B.: A new boundary layer mixing scheme, part I: scheme description and single-column model tests, Mon. Weather Rev., 128, 3187-3199, 2000.

Medeiros, B., Stevens, B., Held, I. M., Zhao, M., Williamson, D. L., Olson, J. G., and Bretherton, C. S.: Aquaplanets, climate sensitivity, and low clouds, J. Climate, 21, 4974-4991, 2008.

Medeiros, B., Williamson, D. L., Hannay, C., and Olson, J. G.: Southeast Pacific stratocumulus in the community atmosphere model, J. Climate, J. Climate, 25, 6175-6192, doi:10.1175/JCLID-11-00503.1, 2012.

Morrison, H. and Gettelman, A.: A new two-moment bulk stratiform cloud microphysics scheme in the Community Atmosphere Model, Version 3 (CAM3), part I: description and numerical 
tests, J. Climate, 21, 3642-3659, 2008.

Neale, R. B., Richter, J. H., and Jochum, M.: The impact of convection on ENSO: from a delayed oscillator to a series of events. J. Climate, 21, 5904-5924, 2008.

Neale, R. B., Gettelman, A., Park, S., Chen, C.-C., Lauritzen, P. H., Williamson, D. L., Conley, A. J., Kinnison, D., Marsh, D., Smith, A. K., Vitt, F., Garcia, R., Lamarque, J.-F., Mills, M., Tilmes, S., Morrison, H., Cameron-Smith, P., Collins, W. D., Iacono, M. J., Easter, R. C., Liu, X., Ghan, S. J., Rasch, P. J., and Taylor, M. A.: Description of the NCAR community atmosphere model (CAM 5.0), NCAR Technical Note, 2011.

Park, S. and Bretherton, C. S.: The University of Washington shallow convection and moist turbulence schemes and their impact on climate simulations with the community atmosphere model, J. Climate, 22, 3449-3469, 2009.

Pincus, R., Hemler, R., and Klein, S. A.: Using stochastically generated subcolumns to represent cloud structure in a large-scale model, Mon. Weather Rev., 134, 3644-3656, 2006.

Randall, D. A.: Conditional instability of the first kind upsidedown, J. Atmos. Sci., 37, 125-130, 1980.

Randall, D. A., Xu, K. M., Somerville, R. J. C., and Iacobellis, S.: Single-column models and cloud ensemble models as links between observations and climate models, J. Climate, 9, 16831697, 1996.

Schubert, W. H., Wakefield, J. S., Steiner, E. J., and Cox, S. K.: Marine stratocumulus convection, part I: governing equations and horizontally homogeneous solutions, J. Atmos. Sci., 36, 12861307, 1979.

Siebesma, A. P., Bretherton, C. S., Brown, A., Chlond, A., Cuxart, J., Duynkerke, P. G., Jiang, H., Khairoutdinov, M., Lewellen, D., Moeng, C.-H., Sanchez, E., Stevens, B., and Stevens, D. E.: A large eddy simulation intercomparison study of shallow cumulus convection, J. Atmos. Sci., 60, 1201-1219, 2003.
Stephens, G. L.: Cloud feedbacks in the climate system: a critical review, J. Climate, 18, 237-273, 2005.

Stevens, B., Ackerman, A. S., Albrecht, B. A., Brown, A. R., Chlond, A., Cuxart, J., Duynkerke, P. G., Lewellen, D. C., Macvean, M. K., Neggers, R. A. J., Sanchez, E., Siebesma, A. P., and Stevens, D. E.: Simulations of trade-wind cumuli under a strong inversion, J. Atmos. Sci., 58, 1870-1891, 2001.

Stevens, B., Moeng, C.-H., Ackerman, A. S., Bretherton, C. S., Chlond, A., De Roode, S., Edwards, J., Golaz, J.-C., Jiang, H., Khairoutdinov, M., Kirkpatrick, M. P., Lewellen, D. C., Lock, A., Muller, F., Stevens, D. E., Whelan, E., and Zhu, P. : Evaluation of large-eddy simulations via observations of nocturnal marine stratocumulus, Mon. Weather Rev., 133, 1443-1462, 2005.

von Salzen, K. and McFarlane, N. A.: Parameterization of the bulk effects of lateral and cloud-top entrainment in transient shallow cumulus clouds, J. Atmos. Sci., 59, 1405-1430, 2002.

Webb, M. J., Senior, C. A., Sexton, M. H., Ingram, W. J., Williams, K. D., Ringer, M. A., McAvaney, B. J., Colman, R., Soden, B. J., Gudgel, R., Knutson, T., Emori, S., Ogura, T., Tsushima, Y., Andronova, N., Li, B., Musat, I., Bony, S., and Taylor, K. E.: On the contribution of local feedback mechanisms to the range of climate sensitivity in two GCM ensembles, Clim. Dynam., 27, 17-38, 2006.

Zhang, G. J. and McFarlane, N. A.: Sensitivity of climate simulations to the parameterization of cumulus convection in the Canadian Climate Centre general circulation model, Atmos.-Ocean, 33, 407-446, 1995.

Zhu, P., Bretherton, C. S., Kohler, M., Cheng, A., Chlond, A., Geng, Q., Austin, P., Golaz, J.-C., Lenderink, G., Lock, A., and Stevens, B. : Intercomparison and interpretation of single-column model simulations of a nocturnal stratocumulus-topped marine boundary layer, Mon. Weather Rev., 133, 2741-2758, 2005. 